\title{
Endogenous spillovers in the trade-off between centralization and decentralization*
}

\author{
Paulo Júlio and Susana Peralta ${ }^{\dagger}$ \\ Department of Economics, Universidade Nova de Lisboa
}

December 11, 2008

\begin{abstract}
In this paper, we revisit the classical trade-off between centralized and decentralized provision of local public goods, in a setting where interregional spillovers depend on the level of a national public good. We compare the standard benevolent planner approach with a political economy in which decisions, in a centralized system, are undertaken by a non-cooperative legislature with no separation of powers. We observe that the policy-maker in a centralized system is able to play both with local public goods and spillovers, a mechanism that is not available under a decentralized system. When compared to the traditional exogenous spillovers assumption, this improves the case for centralization under the standard benevolent planner approach. However, the same is not necessarily true in the non-cooperative legislature, as in this case the interests of the legislator do not need to be aligned with those of the society. Finally, we extend the traditional political economy analysis by considering a legislature in which decisions are undertaken by different committees (separation of powers), and show that it performs better than the original non-cooperative legislature, greatly improving the case for centralization.
\end{abstract}

JEL classification: D70, H11, H41, H70.

Keywords: Local public goods, Spillovers, Fiscal (de)centralization.

\footnotetext{
${ }^{*}$ We thank Miguel Carvalho, José Tavares, Pedro Pita Barros, Steffen Hoernig, Antoine Loeper and all participants in the IRW-FEUNL (May 2008), in the $7^{\text {th }}$ Journées d'Économie Publique Louis-André Gérard-Varet (June 2008) and in the $2^{\text {nd }}$ Annual Meeting of the Portuguese Economic Journal (July 2008) for valuable comments and suggestions. Financial support from Fundação para a Ciência e Tecnologia (BD/36542/2007) is also acknowledged.

${ }^{\dagger}$ Address: Faculdade de Economia, Universidade Nova de Lisboa, Campus de Campolide, 1099-032 Lisboa, Portugal; Phone: + 3512138016 00; Fax: + 351213870933. Corresponding author: Paulo Júlio; E-mail: paulojulio@fe.unl.pt; Webpage: http://docentes.fe.unl.pt/ pjulio.
} 


\section{Introduction}

The literature has, to a great extent, disregarded the impact that different organizational systems might have on the implementation of public goods that generate spillovers, and on the consequent economic effects on the provision of local public goods and welfare. In other words, the analysis of the tradeoff between centralized and decentralized provision of local public goods has been focused on horizontal externalities (between jurisdictions), while assuming that the level of spillovers remains unchanged as we move from one system to the other. We can, however, think of real life situations where this is not necessarily true. For instance, the residents living in metropolitan areas may benefit from several amenities provided in central cities (for example, museums, parks, cultural activities), and vice-versa, but the actual benefit they are able to extract from these amenities depends on the transportation costs or on the time it takes to move across regions (spillovers). ${ }^{1}$ Often, these infrastructures are built jointly by communities (i.e. at a national level), but nevertheless their provision depends on the supply of local amenities in each jurisdiction, which in turn depend on the regime we are in (centralization or decentralization). As another example, in a completely different context, consider a country, like Belgium or Switzerland, where different regions have distinct official languages. In this case, if one citizen intents to enjoy a good play, he will most certainly choose a theater in the region where he lives, since a majority of the population is only able to speak the mother tongue. If the central government chooses a multilingual education policy, then citizens will certainly enjoy greater benefits from plays that are in a different language than their mother tongue (higher benefits from local public goods in other regions). However, the benefits of this policy depend on the supply of theaters, which in turn depend again on the regime we consider.

Hence, different systems can also be characterized by distinct vertical interactions between local public goods and spillovers, which has a clear impact on the supply of spillovers themselves, as well as on welfare and consequently on the trade-off between centralization and decentralization. It is this vertical dimension that characterize the supply of public goods, and that the literature has neglected so far, that we intent to capture and understand here.

The objective of this paper is precisely to revisit this trade-off in a setup where spillovers are endogenous to the political system itself. We consider that the level of spillovers in the society depends on the provision of a national public good, which can be interpreted as the quality of the transportation network connecting jurisdictions, or the investment in a multilingual education system, as in the examples above. This modelization allows us to capture not only the usual horizontal interactions between local public goods in different jurisdictions, but also the vertical interactions between local public goods and the national public good, which will obviously differ depending on the system we consider. Hence, any comparison between centralization and decentralization must be put not is terms of spillovers, but in terms of the cost of providing these spillovers, which constitutes a modification of the decentralization theorems presented in the literature. We also compare the differences induced by this methodology with the traditional exogenous spillovers assumption, identifying the major changes

\footnotetext{
${ }^{1}$ This example was adapted from Bloch and Zenginobuz (2007).
} 
driven by vertical strategic interactions.

We start by analyzing the standard benevolent planner approach, proposed by Oates (1972), as well as a political economy perspective in which the centralized system is based on a non-cooperative legislature with no separation of powers, along the lines of Besley and Coate (2003). We find that the policymaker in a centralized system is able to play at the same time with local public goods and spillovers, shaping the final outcome according to his objective, while in a decentralized system no policy-maker benefits of such advantage, as decisions on local public goods and spillovers are allocated to different tiers of government. We show that, while this improves the case for centralization under the standard approach as compared to the case of exogenous spillovers, the same is not necessarily true in the traditional non-cooperative legislature. The reason is that, in the former, the objectives of the policy-maker are aligned with those of the society, while, in the latter, the appointed legislator under a centralized system will make use of the interaction between local public goods and spillovers to feed his selfish interests, imposing larger costs on the society.

This result left us wondering if there exists an alternative setting that eliminates, or at least limits, the expropriation that the agenda setter is able to impose on the remaining society, when a centralized system is in place. And in fact the answer turns out to be quite simple: a centralized system based on separation of powers, where different committees, composed by distinct members of the legislature (that is, belonging to distinct jurisdictions), are responsible for setting different policy vectors, i.e., one committee is selected to set the provision of local public goods, while the other, possibly with divergent interests, sets the supply of the national public good, determining the level of spillovers. This organizational system not only outperforms the traditional non-cooperative legislature, but also restores the result of the standard approach, i.e., the relative performance of centralization against decentralization is clearly improved as compared to the case of exogenous spillovers, in sense that the range of parameters (preferences and marginal costs) for which the former dominates the latter is increased.

To make these ideas clear, we consider an economy which is composed by two geographically distinct jurisdictions. In each jurisdiction there is a local public good, which benefits not only the citizens in that region, but has also beneficial spillover effects to the other region. Under decentralization, the provision of local public goods is set by the local government, while, in a centralized regime, this task is left to the central authority. The level of spillovers, in turn, depends on the provision of a national public good, which is always decided by the central government.

Under the standard approach, here slightly modified to contemplate the case for endogenous spillovers, all decisions are made by a benevolent government. In a decentralized system, the regional governments choose simultaneously and independently the level of public goods to maximize the surplus of their constituents, while the national government independently sets the level of spillovers in order to maximize aggregate surplus. Under centralization, the central government chooses the amount of local public goods to provide in both regions, as well as the level of spillovers to implement, so as to maximize aggregate surplus. As in Oates (1972), in order to generate some costs for the case of centralization, we impose the ad hoc assumption of "policy uniformity," i.e. the central authority is not able to discriminate local public good provision according to 
regional preferences. This assumption is usually justified on the grounds of information flows, as it is understood that a centralized regime has less knowledge of regional preferences comparing to a government that is "closer to people." Although widely used in fiscal federalism, ${ }^{2}$ as it is an easy way to generate costs for the centralized system without going over the details of the political process, and corroborated by some evidence (Panizza, 1999), this assumption seems unsatisfactory, as it lacks motivation (see Lockwood, 2006). However, it enables us to lay ground for the richer environment of a political economy setup that lies ahead.

Under these standards, the regional governments in a decentralized regime fail to internalize the spillover effect, as the benefits that local public goods might have on the neighbor jurisdiction are not taken into account. Hence, the central authority decides on the amount of spillovers relying upon sub-optimal levels of local public goods. On the other hand, a centralized regime, although not capable of shaping the provision of local public goods to regional preferences, is able not only to internalize interregional spillovers, but also to play with the effects that local public goods have in the optimal provision of spillovers, defining a mix of these variables that takes into account this interaction. It follows that, if the cost of providing the national public good is low, the supply of local public goods should be decided according to the preferences of the whole society, as they could be easily accessed by the other jurisdiction through the implementation of a high level of spillovers. In this case, centralization clearly outperforms decentralization, as the drawback of this system is set to a minimum. The same result holds if the cost of the national public good is high, but preferences are close to each other, as both jurisdictions want similar levels of local public goods. If the cost of the national public good is high and preferences are (significantly) heterogeneous, regional preferences become more relevant to decision-making, as the internalization of spillovers becomes less important. Therefore, a system which is "closer to people" is preferred.

We depart afterwards from this setup, turning our attention to more recent perspectives that explain the trade-off between centralization and decentralization through politics. Our two approaches are based on a non-cooperative legislature, which relies on the citizen candidate framework proposed by Besley and Coate (1997) and Osborne and Al Slivinski (1996). In practical terms, we follow closely the methodology in Besley and Coate (2003), as it constitutes a tractable way to analyze political issues, while allowing for an intuitive modification that allows us to model the level of spillovers within the society.

Under a centralized regime where no separation of powers is allowed, the selfishness of the minimum winning coalition is going to play out, leading to misallocation in the provision of local public goods, and uncertainty both in the provision of local public goods and spillovers. ${ }^{3}$ That is, the legislator who is in charge of setting the policy only takes into consideration the region of his constituents, deploying local public goods in the other jurisdiction according to the benefits he is able to exploit through spillover effects (misallocation), but the identity of this legislator is dependent on who is selected as the agenda

\footnotetext{
2See, for example, Akai and Mikami (2006); Koppel (2005); Cheikbossian (2000). The same idea is also applied on topics related to the size of nations (see Goyal and Staal, 2004; Bolton and Roland, 1997).

${ }^{3}$ The issues of uncertainty and misallocation with respect to local public goods were first presented in Besley and Coate (2003).
} 
setter (uncertainty). On the other hand, a decentralized system, while enabling preference matching in the provision of local public goods, not only does not allow for the internalization of any spillover effects, but may also be characterized by uncertainty in the provision of these spillovers, as the identity of the national legislator is also unknown a priori. The interaction of these forces ultimately determines which system outperforms the other. However, contrary to the standard approach, decentralization comes out of this trade-off in significative advantage, as it may pen up the selfishness interests of the minimum winning coalition. In other words, by allocating decision-making to different tiers of government, decentralization does not allow the central government to play with the interaction between the supply of local and national public goods for his own benefit, eliminating misallocation completely and reducing uncertainty, since the variability of public good allocations is much smaller under this system. It follows that centralization is able to outperform a decentralized regime only if preferences across jurisdictions are similar and the cost of providing spillovers is low enough, since in this case the interests of the agenda setter are to some extent aligned with those of the society. Otherwise, if preferences across jurisdictions are to some extent heterogeneous, it may happen that decentralization always dominates centralization.

Finally, we consider a non-cooperative legislature with separation of powers, such that, under a centralized regime, the supply of local and national public goods is chosen by different members of the legislature representing distinct jurisdictions. This organizational system refrains the selfishness of the members in the legislature, by reducing both misallocation and uncertainty when compared to the case of no separation of powers, while still taking into consideration vertical interactions between the supply of public goods with distinct spacial characteristics. Consequently, the relative performance of centralization against the alternative of decentralization is improved. However, even in this case, the decentralized system may be able to outperform centralization for large degrees of heterogeneity in preferences.

This paper is organized as follows. Section 2 sets up the basic model. Section 3 introduces the optimal solution, making a first approach to the vertical interactions which will be present throughout the paper. Section 4 analyzes the modified standard approach. Section 5 deals with a political economy perspective based on a non-cooperative legislature without separation of powers. Section 6 picks up the previous analysis, while dealing with the case of separation of powers. Section 7 concludes. All proofs are relegated to the appendix.

\section{Related literature}

The analysis of issues related to fiscal decentralization dates back to Tiebout (1956) and Williams (1966), although it was not until the influential work on "Fiscal Federalism," due to Oates (1972), that the trade-off between centralization and decentralization has been put forward for the first time. Along these lines, he has formulated the so called "Decentralization Theorem," which asserts that centralization should only take place once the costs imposed by a uniform provision of local public goods are outweighed by the benefits coming from the internalization of spillovers.

In the subsequent years, no alternative approach has been proposed to ad- 
dress this issue, although the assumption of policy uniformity was understood as non-satisfactory. However, in recent contributions, Lockwood (2002) and Besley and Coate (2003) have put forward an alternative explanation to this trade-off, that is no longer based on this assumption. The idea of these papers consists in bringing politics and institutions into the model, so that an endogenous justification to prefer one system over the other can be found without imposing any ad-hoc assumption that sustains the final conclusion. ${ }^{4}$

The former paper deals predominantly with legislative processes, thereby assuming that citizens within each district are identical and that local public goods consist in one discrete project. The latter, which is much closer to our approach, deals, in its main stream, with political outcomes. It analyzes both a cooperative and non-cooperative legislature, and finds in each one issues that are able to generate an endogenous costs of centralization, therefore creating a trade-off which is settled by the level of spillovers in the society. Under a noncooperative legislature, both misallocation and uncertainty problems come along with a centralized system, reflecting the selfishness interests of the minimum winning coalition, who tries to allocate more spending to the jurisdiction of his constituents. In a cooperative legislature, it is strategic delegation to public good lovers that ends up undermining centralization, which will be characterized by over-provision of public goods. Some recent papers, like the ones by Dur and Roelfsema (2005) on cost sharing, and Schnellenbach et al. (2007) on the likeliness to centralize on a direct versus a representative democracy, have made use of these new approaches to explore further issues on this field.

\section{The basic framework}

For simplicity, let us consider an economy which is divided into 2 geographically distinct districts, indexed by $k \in\{1,2\}$. Each district has a continuum of citizens with a mass of unity. There are 4 goods in the economy: a single private good, $x$; two local public goods, $g_{1}$ and $g_{2}$, each one associated with a particular district; and a national public good, $G$. While the former can be thought of as parks, entertainment places, museums, or even shopping centers, the latter can be, for example, national roads, highways, railways, or even in a subway that connects both districts, lowering transportation costs across jurisdictions and increasing the utility provided by local public goods that are far away. Hence, while local public goods provide utility directly, the role of national public goods is to increase the mobility of individuals across regions, allowing them to appropriate higher benefits from local public goods that are not in their jurisdiction. As such, we consider that the central government is responsible for setting the level of investment in these national public goods.

Citizens are heterogeneous regarding their preference for public goods, denoted by $\theta$. In each district, the range of preference types is $(0, \bar{\theta}]$. The mean type in district $k$, denoted by $m_{k}$, is assumed equal to the median type. ${ }^{5}$ Without loss of generality, consider that districts are ordered such that $m_{1} \geq m_{2}$.

\footnotetext{
${ }^{4}$ For a brief survey on fiscal decentralization under a political economy perspective, see Lockwood (2006).

${ }^{5}$ This formulation allows us to focus on efficiency issues related to public good provision, putting aside distributional considerations, which are not our concern.
} 
We follow Besley and Coate (2003), Dur and Roelfsema (2005) and Schnellenbach et al. (2007), and assume that the preferences of a type $\theta$ individual living in jurisdiction $k$ are given by:

$$
u_{k}(x, \mathbf{g}, G ; \theta)=x+\theta\left[b\left(g_{k}\right)+K(G) \cdot b\left(g_{l}\right)\right] ; k, l=1,2 ; k \neq l
$$

where $\mathbf{g}=\left(g_{1}, g_{2}\right)$. The functions $b\left(g_{k}\right): \mathbb{R}_{+} \mapsto \mathbb{R}_{+}$and $K(G): \mathbb{R}_{+} \mapsto[0,1)$ are twice continuous differentiable, strictly increasing and strictly concave. Both satisfy the Inada conditions. One permissible class of functions, which will be useful later on to illustrate the workings of the model, is $b\left(g_{k}\right)=g_{k}^{\alpha}$ and $K(G)=\frac{G^{\beta}}{G^{\beta}+1}$, with $\alpha, \beta \in(0,1)$.

It is clear in this formulation that citizens benefit not only from the public good in their district, but also from the public good in the other district. The size of this effect depends on the amount of the national public good available. Notice that the spillover effect is the same for all citizens, irrespective of their type; what changes is the individual benefit provided by local public goods, such that those with higher $\theta$ value them more heavily. Furthermore, we rule out situations where the public good in the other district is more valued by citizens than their own public good.

The marginal cost of producing both local and national public goods is assumed constant. In order to produce one unit of a local public good, $\rho$ units of the private good are required, while producing one unit of the national public good requires $\gamma$ units of the private good.

Under a decentralized system, the level of provision of the local public good in each district is chosen by the government of that district, and is financed by a uniform head tax levied on local residents. Thus, if district $k$ chooses a public good level $g_{k}$, each citizen in this district pays a tax of $\rho g_{k}$. Under a centralized system, local public good provision in each district is determined by the central authority and financed by a uniform head tax levied on all citizens. Hence, public good levels $g_{1}$ and $g_{2}$ imply a head tax of $\gamma \frac{g_{1}+g_{2}}{2}$ in each district. ${ }^{6}$ The national public good is always chosen centrally, and financed through a uniform tax levied on all citizens of $\gamma G$, which is distributed evenly across jurisdictions. It is assumed that agents are endowed with enough private good to pay their tax obligations. ${ }^{7}$

\section{The optimal solution}

For later reference, let us find the optimal levels for both local public goods and for the national public good. Under the usual assumption that the social

\footnotetext{
${ }^{6}$ This approach follows the main stream in the literature (see Besley and Coate, 2003; Redoano and Scharf, 2004; Dur and Roelfsema, 2005).

${ }^{7}$ Observe that, in this setup, a higher value for $\gamma$ may just reflect the fact that the districts are relatively far from each other, or are separated by some kind of natural barrier or obstacle, which increases the cost of building an infrastructure that connects both regions. For example, there may be the need to build bridges, tunnels, or to employ longer routes, that require higher levels of investment to attain the same amount of spillovers, resulting in a higher value for $\gamma$.
} 
planner maximizes the unweighted sum of utilities, ${ }^{8}$ the program to solve is: ${ }^{9}$

$$
\max _{\mathbf{g}, G}\left[m_{1}+m_{2} K(G)\right] \cdot b\left(g_{1}\right)+\left[m_{2}+m_{1} K(G)\right] \cdot b\left(g_{2}\right)-\rho\left(g_{1}+g_{2}\right)-\gamma G
$$

The surplus maximizing levels of public goods, denoted by $\left(g_{1}^{o}, g_{2}^{o}, G^{o}\right)$, are implicitly given by: ${ }^{10}$

$$
\begin{aligned}
b^{\prime}\left(g_{1}^{o}\right) & =\frac{\rho}{m_{1}+m_{2} K\left(G^{o}\right)} \\
b^{\prime}\left(g_{2}^{o}\right) & =\frac{\rho}{m_{2}+m_{1} K\left(G^{o}\right)} \\
K^{\prime}\left(G^{o}\right) & =\frac{\gamma}{m_{1} b\left(g_{2}^{o}\right)+m_{2} b\left(g_{1}^{o}\right)}
\end{aligned}
$$

As $m_{1}$ exceeds $m_{2}$, district $1^{\prime} s$ level of public good provision is obviously higher, as the mean citizen is more pro-public spending in district 1 than his counterpart in district 2. Also, some algebra allows us to conclude that an increase in $G$ originates a higher optimal level of local public goods. This happens because a higher level of provision of the national public good allows the citizens in each jurisdictions to benefit more from the spillovers created by local public goods that are in the other district. Hence it becomes optimal to also provide a greater amount of local public goods, as the benefits spread much faster to the neighbor district.

Equation (4) states that the optimal level of $G$ is such that the marginal benefit equals the marginal cost of providing one more unit of the national public good. While the marginal cost is just the amount citizens have to pay for one more unit of the national public good, the marginal benefit is the sum across all jurisdictions of the spillovers created by each local public good, due to a marginal increase in the level of $G$.

\section{The modified standard approach}

In this section, we take up on Oates' (1972) approach, and assume that decisionmakers are benevolent, in sense that they maximize the welfare of their jurisdiction (in the case of decentralization), or of the whole economy (in the case of centralization).

Some assumptions on the timing of decisions regarding the decentralized system must be made. We consider that, in the first stage of the game, national authorities choose the level of the national public good that maximizes aggregate

\footnotetext{
${ }^{8}$ Note that, as both jurisdictions are exactly symmetric ex-ante, there are no equity issues and the utility function is quasi-linear (hence, the marginal utility of private consumption is equal across jurisdictions), the utilitarian approach is perfectly suitable for the present context.

${ }^{9}$ It can be shown that, without further assumptions, the first order conditions might define a saddle point and more than one local maxima. In order to rule out these situations, which add nothing to the current discussion, and to impose uniqueness on the solution, we further assume that the term $\left[m_{1} b\left(g_{2}^{o}(G)\right)+m_{2} b\left(g_{1}^{o}(G)\right)\right] \cdot K^{\prime}(G)$ is decreasing in $G$. That is, the marginal benefit for the society from the national public good along the optimal path for both local public goods must be decreasing.

${ }^{10}$ The proof is provided in the appendix.
} 
surplus, and thereafter local decision-makers choose simultaneously the supply of the local public good in order to maximize the surplus in the district where they belong. ${ }^{11}$ In the centralized system, there is no such issue, as the policymaker chooses all policy variables in order to maximize aggregate surplus.

\subsection{The decentralized solution}

Let us work by backward induction. In the second stage, both jurisdictions are going to decide simultaneously and independently the provision of local public goods, given the level of $G$ chosen by the central authority. The local government in jurisdiction $k$ will solve:

$$
\max _{g_{k}} m_{k}\left[b\left(g_{k}\right)+K(G) \cdot b\left(g_{l}\right)\right]-\rho g_{k}-\frac{\gamma}{2} G ; k, l=1,2 ; k \neq l
$$

The outcome of this problem yields an equilibrium in dominant strategies, which simplifies the exposition greatly. As jurisdictions only care about their own public good, ignoring spillover effects to other districts, and cannot influence the decision-making of the remaining local authorities in order to appropriate their spillovers, as decisions are undertaken in an independent fashion, it is easy to see that the only outcome of this problem, denoted by $\left(g_{1}^{d}, g_{2}^{d}\right)$, must be:

$$
b^{\prime}\left(g_{k}^{d}\right)=\frac{\rho}{m_{k}} ; k=1,2
$$

Hence, expenditures in local public goods are independent on the level of the national public good, $G$. It is immediate to see that this results in underprovision of all local public goods relatively to the optimal solution.

In the first stage, the central authority decides the level of the national public good, given condition (5):

$G^{d}=\arg \max _{G}\left[m_{1}+m_{2} K(G)\right] \cdot b\left(g_{1}^{d}\right)+\left[m_{2}+m_{1} K(G)\right] \cdot b\left(g_{2}^{d}\right)-\rho\left(g_{1}^{d}+g_{2}^{d}\right)-\gamma G$

The first order condition reads:

$$
\left[m_{1} b\left(g_{2}^{d}\right)+m_{2} b\left(g_{1}^{d}\right)\right] \cdot K^{\prime}\left(G^{d}\right)=\gamma
$$

Notice that equation (6) is very similar to (4). In both situations, we are considering a benevolent central authority, but, in the former, she has no control over local provision of public goods, while in the latter she sets both national and local public goods. This implies the same decision rule, but evaluated at different levels of $\mathbf{g}=\left(g_{1}, g_{2}\right)$. Furthermore, in the present case, an increase in the provision of national public goods only allows citizens to benefit more from existing local public goods. Therefore, there are fewer incentives to spread spillovers across jurisdictions, resulting in under-provision of the national public good.

To sum up, local policy-makers fail to internalize the spillover effects originated by the national public good. As such, the national government underinvests on the propagation of spillovers, as she is not able to convince local

\footnotetext{
${ }^{11}$ It turns out that in equilibrium the level of provision of all public goods is independent on whether decisions are made sequentially or simultaneously, and on the assumed timing. This is true as the provision of local public goods below is not a function of $G$.
} 
governments to increase the supply of local public goods in order to maximize the appropriation of spillovers in the society. Henceforth, the surplus is lower than what might otherwise have been.

\subsection{The centralized solution}

Considering $g_{1}=g_{2}=g$, the central authority chooses a uniform supply of local public goods and a level of the national public good that solves:

$$
\max _{g, G}\left(m_{1}+m_{2}\right) \cdot[1+K(G)] \cdot b(g)-2 \rho g-\gamma G
$$

This formalization implies that the decision-maker maximizes the sum across jurisdictions of all benefits originated by local public goods, taking into account that each one originates a direct effect in the district where it is provided and a spillover effect, which depends on the level of the national public good, affecting the other jurisdiction. The first order condition for $g$ yields: ${ }^{12}$

$$
b^{\prime}\left(g^{c}\right)=\frac{\rho}{\bar{m}\left[1+K\left(G^{c}\right)\right]}
$$

where $\bar{m}=\frac{m_{1}+m_{2}}{2}$, and $G^{c}$ is defined implicitly by the following application:

$$
\bar{m} b\left(g^{c}\right) \cdot K^{\prime}\left(G^{c}\right)=\frac{\gamma}{2}
$$

Hence, the decision-maker provides the local public good up to a point where its average marginal benefit, which comprises the average direct benefit plus the average benefit created through spillover effects, is exactly offset by the marginal cost of providing it. Contrary to the decentralized solution, the central authority internalizes the spillover effect, as she responds positively to a higher level of the national public good, increasing the provision of local public goods. The drawback is that she does not take into account the heterogeneity among different districts in the economy, producing a "one size fits all" public good. Equation (8) has the same interpretation as (4), except that now the level of local public goods is uniform.

\subsection{Centralization vs Decentralization: A brief discussion}

From the previous discussion, it is immediate that the level of spillovers differ, depending on which regime we are in. This new issue introduces a new dimension in the classical trade-off between centralization and decentralization, to which analysis we now turn.

For further discussion, it is convenient to define the maximum level of surplus attained under each system. For decentralization, we have: ${ }^{13}$

\footnotetext{
${ }^{12}$ See the appendix for a sketch of the proof.

Again, in order to avoid dealing with saddle points and possibly multiple local maximizers, which unnecessarily complicate the current analysis, we consider that the term $\bar{m} b\left(g^{c}(G)\right) \cdot K^{\prime}(G)$ is decreasing in $G$.

${ }^{13}$ For notational convenience, we suppress the dependence of welfare and public good allocations on the exogenous parameters of the model, i.e., preferences and marginal costs.
} 


$$
\begin{aligned}
W^{d} & =m_{1}\left[b\left(g_{1}^{d}\right)+K\left(G^{d}\right) \cdot b\left(g_{2}^{d}\right)\right]+m_{2}\left[b\left(g_{2}^{d}\right)+K\left(G^{d}\right) \cdot b\left(g_{1}^{d}\right)\right]- \\
& -\rho\left(g_{1}^{d}+g_{2}^{d}\right)-\gamma G^{d}
\end{aligned}
$$

And for centralization:

$$
W^{c}=2 \bar{m} \cdot\left[1+K\left(G^{c}\right)\right] \cdot b\left(g^{c}\right)-2 \rho g^{c}-\gamma G^{c}
$$

\subsubsection{Homogenous preferences}

Assume that both jurisdictions have the same preference parameter for public goods, i.e., $m_{1}=m_{2}$. In this case, it is actually optimal to set a uniform level of local public goods, and therefore the disadvantage of a centralized system is minimized. Hence, while in a decentralized system, local decision-makers do not have incentives to take into account the spillovers originated by local public goods, as they do not benefit from them, in the centralized system the policymaker is able to internalize fully and correctly all spillover effects. Therefore, she takes into account the complete interaction between both local public goods and the national public, consequently increasing the level of welfare in the society as compared to decentralization. This argumentation enables us to draw the following proposition:

Proposition 1. Under homogeneous preferences, the centralized system delivers a higher welfare as compared to the decentralized system.

This result is similar to Besley and Coate (2003), except that now spillovers are never absent from the society. This implies that the situation of no spillovers is ruled out, and centralization yields a superior performance as compared to a decentralized regime.

\subsubsection{Heterogenous preferences}

If districts are heterogeneous, the comparison between centralization and decentralization becomes opaque, as the difference in welfare, $W^{c}-W^{d}$ may not necessarily be monotone in $\gamma$ for all possible specifications of the function $b(g)$ and for all $\left(m_{1}, m_{2}, \rho\right)$. In order to deal with this extra complication that arises under this scenario, we will work in a more specific setup, defining the benefit from local public goods as:

$$
b(g)=g^{0.5}
$$

Under (11), the following proposition, which states a modified version of the decentralization theorem, can then be put forward: ${ }^{14}$

Proposition 2. If districts have heterogeneous preferences, then there exists a critical value $\hat{\gamma}$ such that the level of surplus under the centralized and decentralized systems coincide. The decentralized system (strictly) dominates centralization if and only if $\gamma>\hat{\gamma}$; otherwise centralization allows a higher welfare.

\footnotetext{
${ }^{14}$ Proposition 2 remains valid under a more general setup. A sufficient condition for it to hold is that the function $b(g)$ satisfies:

$$
m_{1}\left[b\left(g^{c}\right)-b\left(g_{2}^{d}\right)\right]+m_{2}\left[b\left(g^{c}\right)-b\left(g_{1}^{d}\right)\right]>0
$$
}


If the cost of providing the national public good is low, it becomes optimal from the society's point of view to supply similar amounts of local public goods in both jurisdictions, as the benefits conveyed by them could be given a national relevance through the supply of a high level of a low cost national public good. In other words, the supply of local public goods becomes a national issue, as the benefits can be scattered easily throughout the society, and hence it should be decided according to the average preference of the society. This implies that the drawback of the centralized system is set to a minimum, while a decentralized regime, by ignoring the spillover effects, would attain a level of surplus far way from these standards. On the other hand, for higher values of $\gamma$, it becomes optimal from the society's point of view to supply a reduced amount of the national public good, and consequently local public goods should be provided according to individual preferences of each jurisdiction. This implies that decentralization provides a better match, while a centralized regime would simply mismatch individual preferences.

This result presents a main difference as compared to the usual decentralization theorem, as it does not use critical values for spillovers, but rather states the trade-off between centralization and decentralization in terms of the cost of providing these spillovers. As for the same $\gamma$ these systems provide different amounts of spillovers, this variable becomes more appropriate to the present analysis. For example, we could take $G$ as an index of the quality of an infrastructure connecting both districts and $\gamma$ to be the unitary cost per unit of quality. In this perspective, building a high quality transportation network would be much cheaper if districts were close to each other than if they were far way, or separated by natural barriers or obstacles. According to this proposition, the case for centralization would be much stronger in the former situation, while the latter would call for a decentralized approach.

\section{An example}

We now illustrate these results in a fully specified setup. Assume the following specifications:

$$
b\left(g_{k}\right)=g_{k}^{0.5} \quad \text { and } \quad K(G)=\frac{G^{0.5}}{G^{0.5}+1}
$$

Also, let $\rho=1$ and $\bar{m}=5$. Changing these parameters only affects the responsiveness of the relationships, but not the main conclusions. ${ }^{15}$ The assumption regarding the last parameter is established so that we are allowed to impose changes in $m_{1}$ and $m_{2}$ without interfering on the average preference for public goods in the society. Hence, $m_{1}-m_{2} \in[0,10)$. Figure 1 represents the relative performance of centralization against decentralization, in the space $\left(m_{1}-m_{2}, \gamma, W^{c}-W^{d}\right)$.

Several issues should be pointed out. If preferences are homogeneous, decentralization is always dominated, as the assumption of policy uniformity does not impose any cost on the centralized regime. However, as the degree of heterogeneity increases, the cutoff $\widehat{\gamma}$ for which centralization dominates decentralization

\footnotetext{
${ }^{15}$ The marginal cost of local public goods can be thought of as a normalization. The choice of the average preference for public goods was made for graphical convenience.
} 


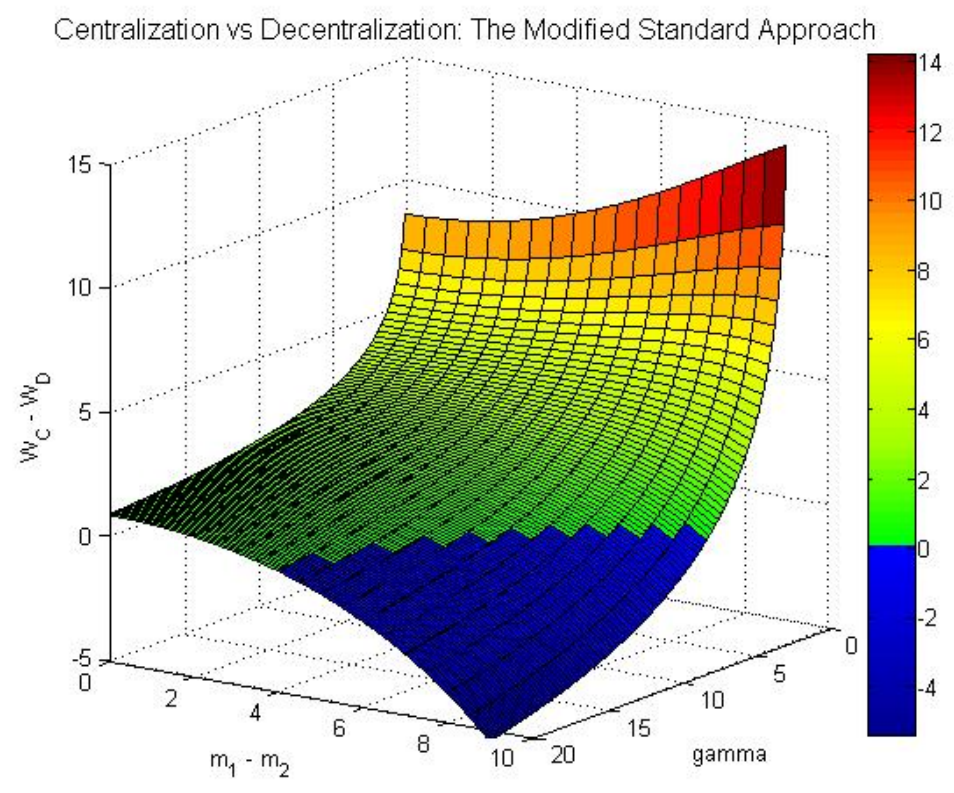

Figure 1: Difference in welfare between centralization and decentralization.

decreases. ${ }^{16}$ This illustrates the cost of centralization: as preferences become farther apart, for a given $\gamma$, the cost imposed by uniform provision becomes larger, and centralization only remains a better option if it is allowed to appropriate larger benefits from the interaction between local and national public goods, which, in turn, requires a lower $\gamma$ (see also figure 2 below).

To put the same idea differently, we can think that, as $\gamma$ increases and spillovers become more expensive, the gains obtained from centralization diminish, and public good provision based on local needs becomes more important than internalizing spillovers. ${ }^{17}$

\subsection{A comment on endogenous spillovers}

Let us resume the general setup presented in section 2. As we had mentioned before, local policy-makers in the decentralized system are not able to internalize the spillover effects, as they ignore any benefit that local public goods might have on the neighbor districts. This implies that the national government can do no better than to optimize over this behavior of his local counterparts, and so the implicit relationship between the provision of local and national public goods is not taken into account. Hence, the performance of the decentralized system with endogenous spillovers is similar, in almost all aspects, to the traditional

\footnotetext{
${ }^{16}$ Observe that this cutoff does not start at $m_{1}-m_{2}=0$, because we limited the range of values $\gamma$ is allowed to take.

${ }^{17}$ Note that it is not correct to draw conclusions on the magnitude of the differences in welfare. As changes in $m_{1}$ and $m_{2}$ also have a direct impact on welfare, increases in this magnitude may not indicate that the centralized system is performing "relatively better."
} 
approach widely presented in the literature. ${ }^{18}$ On the other hand, the policymaker in the centralized system is able to play with both local and national public goods, taking into account the optimal interaction between them. This further instrument, which was not available in the traditional approach with exogenous spillovers, broadly improves the performance under centralization, as pointed out in the following result:

Proposition 3. Endogenous spillovers never improve the case for decentralization, in sense that the space of parameters $\left(m_{1}, m_{2}, \rho, \gamma\right)$ such that decentralization dominates centralization is (weakly) larger when spillovers are exogenous.

\section{Example (continued)}

We return to the example introduced above to illustrate this result. Figure 2 represent the contour lines of the difference in welfare between centralization and decentralization, both for exogenous and endogenous spillovers. The steps used to construct this figure follow closely the proof of proposition $3 .^{19}$

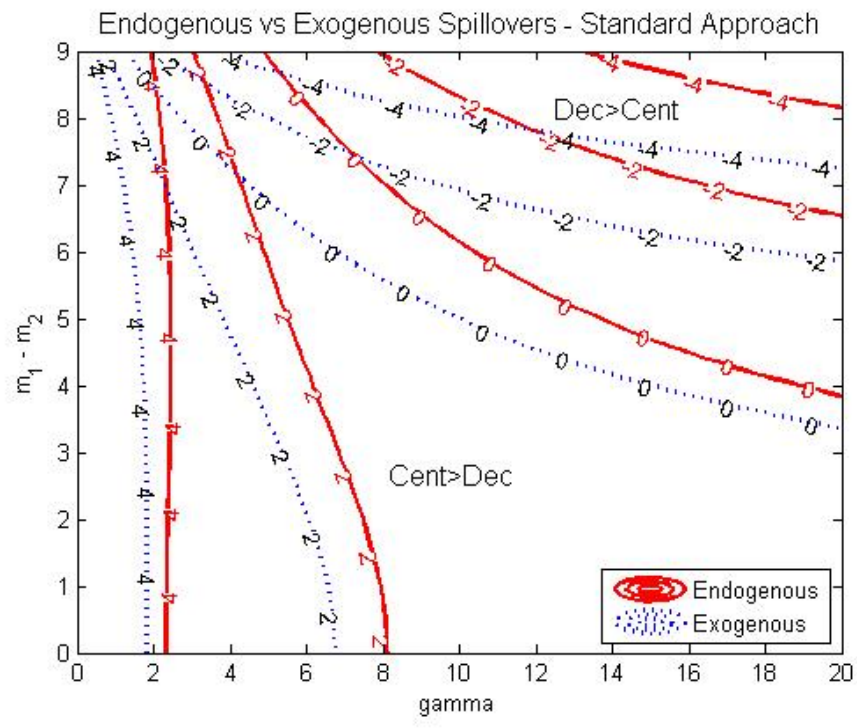

Figure 2: Contour lines of the difference in welfare between centralization and decentralization, for the cases of endogenous and exogenous spillovers.

The important lines to retain from this figure are the zero-contour lines, which represent the set of parameters in the space $\left(m_{1}-m_{2}, \gamma\right)$ for which the welfare under centralization and decentralization coincide, given $\rho$. We can observe that, when endogenous spillovers are considered, the region where

\footnotetext{
${ }^{18}$ Note that we use the word "almost" to safeguard for the fact that, in the current setup, spillovers still have to be paid, an issue that is not present in the traditional approach.

${ }^{19}$ In fact, the mechanic is exactly the same. We start by building a mapping between $\gamma$ and $\kappa$ the level of spillovers, using the function $\kappa=K\left(G^{d}\right)$, which allows us to represent the case of exogenous spillovers in the space $\left(m_{1}-m_{2}, \gamma\right)$, given $\rho$. Then, we plot the contour lines for the endogenous spillovers case.
} 
centralization outperforms decentralization is increased. In other words, when endogenous spillovers are introduced, centralization gains a new mechanism to increase welfare, which is not available in a decentralized system - the ability to endogenize the strategic interaction between centrally and locally provided public goods. Hence, decentralization can only outperform centralization if the cost imposed by uniform provision increases enough to compensate the gain brought to centralization by the vertical dimension of the problem, and this can only be achieved through an increase in the degree of heterogeneity in preferences or through an increase in the cost the national public good.

\section{A modified political economy approach}

We now model political decision-making, based on the citizen-candidate frameworks proposed in Besley and Coate (1997) and Osborne and Al Slivinski (1996). It is assumed that decision-makers cannot commit themselves to a given policy platform prior to the election stage, and therefore they always follow their preferred policies once in office. Hence, citizens elect policy-makers whose preferences match the ones they like. Policy preferences are common knowledge, and there is no cost of entering into politics.

\subsection{Policy determination under decentralization}

Under decentralization, it is assumed that the provision of the national public good is decided by the national legislature, while elected regional representatives are responsible for setting the supply of local public goods in each jurisdiction. We model this by setting up a four stage process, consisting of: ${ }^{20}$

- Stage 1: Citizens in each jurisdiction elect a legislator, among its members, to the national legislature, by majority voting.

- Stage 2: The legislature chooses the provision of the national public good, under the rules defined below.

- Stage 3: Citizens in each jurisdiction elect a policy-maker, among its members, to the regional government, by majority voting. The legislator appointed to the national legislature cannot run to the regional elections.

- Stage 4: Local policy-makers in each jurisdiction choose simultaneously and independently the supply of local public goods to provide in order to maximize their payoffs.

\footnotetext{
${ }^{20}$ Although we build a four stage process, the final result holds if we consider a two stage process where, in the first stage, all citizens vote simultaneously and independently for the national legislature and for the regional government, and, in the second stage, all elected legislators set, simultaneously and independently, the provision of public goods which they are responsible for, in order to maximize their payoffs. Reversing the order of decisions (i.e., having local decisions first and national decisions afterwards), however, brings new elements to the model, by creating strategic interaction at the local level, which, in turn, induces strategic delegation. In this case, there is a positive probability that local policy-makers in one region can use local public goods to influence the level of spillovers implemented by the legislature, and these will depend on the decision of the other region. Although interesting, this issue is better left for a full treatment in a separate paper.
} 
The assumption that the legislator elected in stage 1 cannot run to regional elections can be interpreted as a separation of powers, and avoids issues of strategic voting when citizens elect their representative to serve in the legislature. As usual, we look for a Subgame Perfect Nash Equilibrium. Let the type of the elected policy-maker in stage 3 in district $k$ be given by $\theta_{k}, k=1,2$. Working by backward induction, and recalling that elected citizens follow their preferred policies when in office, the provided level of local public goods in district $k$ is the solution to the following problem:

$$
\max _{g_{k}} \theta_{k}\left[b\left(g_{k}\right)+K(G) \cdot b\left(g_{l}\right)\right]-\rho g_{k}-\frac{\gamma}{2} G ; k, l=1,2 ; k \neq l
$$

The first order condition reads:

$$
b^{\prime}\left(g_{k}\left(\theta_{k}\right)\right)=\frac{\rho}{\theta_{k}}
$$

Hence, elected policy-makers only care about the net benefit provided by the local public good to themselves, neglecting any spillover effects over the other jurisdiction.

In the third stage, citizens vote to elect the policy-maker who will set $g_{k}$. A citizen of type $\theta$ in district $k$ will enjoy a level of surplus defined by:

$$
W_{k}^{\theta}\left(\theta_{k} ; \theta_{l}, G\right)=\theta\left[b\left(g_{k}\left(\theta_{k}\right)\right)+K(G) \cdot b\left(g_{l}\left(\theta_{l}\right)\right)\right]-\rho g_{k}\left(\theta_{k}\right)-\frac{\gamma}{2} G
$$

for $k, l=1,2 ; k \neq l$. These preferences over types determine citizens' voting decisions. Following Besley and Coate (2003), a pair of representative types $\left(\theta_{1}^{*}, \theta_{2}^{*}\right)$ is majority preferred under decentralization if, in each district $k$, a majority of citizens prefers the type of their representative to any other type $\theta \in(0, \bar{\theta}]$, given the type of the other district's representative $\theta_{l}, l \neq k$. As preferences over types are single-peaked, the application of the median voter theorem implies that a pair of representative types $\left(\theta_{1}^{*}, \theta_{2}^{*}\right)$ is majority preferred if and only if it is a median pair, i.e., $\left(\theta_{1}^{*}, \theta_{2}^{*}\right)=\left(m_{1}, m_{2}\right)$. Thus, we have established that:

$$
\left(b^{\prime}\left(g_{1}^{p d}\right), b^{\prime}\left(g_{2}^{p d}\right)\right)=\left(\frac{\rho}{m_{1}}, \frac{\rho}{m_{2}}\right)
$$

Under the assumption that the median voter is equal to the mean voter, local public good provision in our political economy framework agrees with the standard analysis.

Let us now turn our attention towards the second stage of the process. At this point, it is necessary to define the rules of how the legislature behaves. There is no unified approach in the literature, although a number of different alternatives have been suggested (see Lockwood, 2006). Here, we will use a slightly modified version of the closed rule legislative bargaining proposed in a seminal paper by Baron and Ferejohn (1989), and used in Besley and Coate (2003). Let the type of the elected legislator in jurisdiction $k$ in stage 1 be given by $\theta_{k}^{\prime}, k=1,2$. In stage 2 , one of the two legislators is randomly appointed to be the agenda setter. He can then make a proposal for the level of $G$, which must find the support of a minimum winning coalition. In our two jurisdiction model, and again following Besley and Coate (2003), each legislator can be thought of 
as a minimum winning coalition, as he represents exactly half of the electorate. Hence, a type $\theta_{k}^{\prime}$ agenda setter implements:

$$
G_{k}\left(\theta_{k}^{\prime}\right)=\arg \max _{G} \theta_{k}^{\prime}\left[b\left(g_{k}^{p d}\right)+K(G) \cdot b\left(g_{l}^{p d}\right)\right]-\rho g_{k}^{p d}-\frac{\gamma}{2} G ; k \neq l
$$

It can be checked that $G_{k}\left(\theta_{k}^{\prime}\right)$ is defined implicitly by:

$$
\theta_{k}^{\prime} b\left(g_{l}^{p d}\right) \cdot K^{\prime}\left(G_{k}\left(\theta_{k}^{\prime}\right)\right)=\frac{\gamma}{2} ; k \neq l
$$

Notice that the left hand side is just the marginal benefit of $G$ for a type $\theta_{k}^{\prime}$ citizen in jurisdiction $k$, which is generated through the spillovers of the local public good in jurisdiction $l$, while the right hand side is the marginal cost of providing one more unit of $G$ for his jurisdiction.

In the first stage, citizens in each jurisdiction elect the legislator who will take part in the national legislature. As in stage 2 each delegate can be appointed as the agenda setter with probability $1 / 2$, the expected surplus of a type $\theta$ citizen in jurisdiction $k$ is given by:

$$
\begin{aligned}
& E W_{k}^{\theta}\left(\theta_{k}^{\prime}, \theta_{l}^{\prime}\right)= \\
= & \frac{1}{2}\left[\theta\left[b\left(g_{k}^{p d}\right)+K\left(G_{k}\left(\theta_{k}^{\prime}\right)\right) \cdot b\left(g_{l}^{p d}\right)\right]-\rho g_{k}^{p d}-\frac{\gamma}{2} \widehat{G}_{k}\left(\theta_{k}^{\prime}\right)\right] \\
+ & \frac{1}{2}\left[\theta\left[b\left(g_{k}^{p d}\right)+K\left(G_{l}\left(\theta_{l}^{\prime}\right)\right) \cdot b\left(g_{l}^{p d}\right)\right]-\rho g_{k}^{p d}-\frac{\gamma}{2} \widehat{G}_{l}\left(\theta_{l}^{\prime}\right)\right]
\end{aligned}
$$

for $k, l=1,2 ; k \neq l$. Once again, citizens prefer a candidate of their own type. ${ }^{21}$ As preferences over types are single-peaked, ${ }^{22}$ an analogous argumentation to the one used previously allows us to state that a pair of types $\left(\theta_{1}^{\prime *}, \theta_{2}^{\prime *}\right)$ is majority preferred if and only if it is a median pair. Hence, $\left(\theta_{1}^{\prime *}, \theta_{2}^{\prime *}\right)=\left(m_{1}, m_{2}\right)$, and the supplied level of $G$ is:

$$
G^{p d}= \begin{cases}K^{\prime-1}\left(\frac{\gamma}{2 m_{1} b\left(g_{2}^{p d}\right)}\right) & \text {, with prob. } \frac{1}{2} \\ K^{\prime-1}\left(\frac{\gamma}{2 m_{2} b\left(g_{1}^{p d}\right)}\right) & \text {, with prob. } \frac{1}{2}\end{cases}
$$

This result no longer coincides with the standard analysis, unless both districts are perfectly homogeneous. As there is a conflict of interests among the two delegates in the national legislature, due to differences in the preference parameter for public goods, each one finds optimal to generate a different level of spillovers, and consequently to provide a different level of $G$. As $G^{p d}$ depends on the candidate selected to be the agenda setter, this will introduce uncertainty over the implemented level of the national public good, which gets worse as preferences become farther apart.

\footnotetext{
${ }^{21}$ Taking the derivative of $E W_{k}^{\theta}\left(\theta_{k}^{\prime}\right)$ with respect to $\theta_{k}^{\prime}$ yields:

$$
\theta b\left(g_{l}^{p d}\right) \cdot K^{\prime}\left(\widehat{G}_{k}\left(\theta_{k}^{\prime}\right)\right)=\frac{\gamma}{2} \Leftrightarrow \theta=\theta_{k}^{\prime}
$$$$
\text { where we used the fact that } K^{\prime}\left(\widehat{G}_{k}\left(\theta_{k}^{\prime}\right)\right)=\frac{\gamma}{2 \theta_{k}^{\prime} b\left(g_{l}^{p d}\right)} \text {. }
$$

${ }^{22}$ As there is a one to one mapping between $\theta_{k}^{\prime}$ and $G_{k}\left(\theta_{k}^{\prime}\right)$, with $\frac{\mathrm{d}}{\mathrm{d} \theta_{k}^{\prime}} G_{k}\left(\theta_{k}^{\prime}\right)>0$, one can check instead that $\frac{\mathrm{d}^{2}}{\mathrm{~d} G^{2}} E W_{k}^{\theta}(G)<0$, which is a much easier task.
} 


\subsection{Policy determination under centralization with no sep- aration of powers}

Under centralization, the policy vector $(\mathbf{g}, G)$ is chosen by the national legislature, and all costs are split uniformly across jurisdictions. The order of events is as follows:

- Stage 1: Citizens in each jurisdiction elect a representative (delegate) among them, by majority voting. Elected representatives compose the national legislature.

- Stage 2: The legislature chooses the policy-vector $(\mathbf{g}, G)$.

As usual, we start analyzing the last stage. Let $\theta_{k}$ be the type of the elected legislator for district $k$ in stage $1, k=1,2$. The rules of the legislative bargaining are the same as for the decentralization case, except that now the agenda setter chooses the whole policy-vector: centralization with no separation of powers. Thus, if selected by nature, the type $\theta_{k}$ legislator will solve:

$$
\max _{g_{k}, g_{l}, G} \theta_{k}\left[b\left(g_{k}\right)+K(G) \cdot b\left(g_{l}\right)\right]-\rho \frac{g_{k}+g_{l}}{2}-\frac{\gamma}{2} G ; k \neq l
$$

The supply of local public goods is: ${ }^{23}$

$$
\begin{aligned}
b^{\prime}\left(g_{k}\left(\theta_{k}\right)\right) & =\frac{\rho}{2 \theta_{k}} \\
b^{\prime}\left(g_{l}\left(\theta_{k}, G_{k}\left(\theta_{k}\right)\right)\right) & =\frac{\rho}{2 \theta_{k} K\left(G_{k}\left(\theta_{k}\right)\right)}
\end{aligned}
$$

and the implemented level of the national public good, $G_{k}\left(\theta_{k}\right)$, is:

$$
\theta_{k} b\left(g_{l}\left(\theta_{k}, G_{k}\left(\theta_{k}\right)\right)\right) \cdot K^{\prime}\left(G_{k}\left(\theta_{k}\right)\right)=\frac{\gamma}{2}
$$

Hence, the legislator in jurisdiction $k$, if appointed to be the agenda setter, chooses $g_{k}$ according to his direct benefit, but only provides $g_{l}$ up to a point where the spillover effect enables him to extract a positive net marginal benefit from the local public good in the other jurisdiction. Observe also that equation (20) is very similar to equation (15), as in both situations the agenda setter chooses the level of $G$ according to the spillovers that the local public good in the other jurisdiction is able to generate to him.

Now, to the workings of the first stage. Each delegate is chosen to be the agenda setter with probability $1 / 2$. Hence, the expected surplus of a type $\theta$ citizen in district $k$ in stage 1 is given by:

\footnotetext{
${ }^{23}$ The proof follows similar steps to the ones used for the centralized case in the modified standard approach. However, the assumption to make here is:

$$
\frac{\mathrm{d}}{\mathrm{d} G_{k}}\left[\theta_{k} b\left(g_{l}\left(\theta_{k}, G_{k}\right)\right) \cdot K^{\prime}\left(G_{k}\right)\right]<0, \forall \theta_{k}
$$
}




$$
\begin{aligned}
& E W_{k}^{\theta}\left(\theta_{k}, \theta_{l}\right)= \\
= & \frac{1}{2} \theta\left[b\left(g_{k}\left(\theta_{k}\right)\right)+K\left(G_{k}\left(\theta_{k}\right)\right) \cdot b\left(g_{l}\left(\theta_{k}, G_{k}\left(\theta_{k}\right)\right)\right)\right]- \\
- & \frac{1}{2}\left[\rho \frac{g_{k}\left(\theta_{k}\right)+g_{l}\left(\theta_{k}, G_{k}\left(\theta_{k}\right)\right)}{2}+\frac{\gamma}{2} G_{k}\left(\theta_{k}\right)\right]+ \\
+ & \frac{1}{2} \theta\left[b\left(g_{k}\left(\theta_{l}, G_{l}\left(\theta_{l}\right)\right)\right)+K\left(G_{l}\left(\theta_{l}\right)\right) \cdot b\left(g_{l}\left(\theta_{l}\right)\right)\right]- \\
- & \frac{1}{2}\left[\rho \frac{g_{k}\left(\theta_{l}, G_{l}\left(\theta_{l}\right)\right)+g_{l}\left(\theta_{l}\right)}{2}+\frac{\gamma}{2} G_{l}\left(\theta_{l}\right)\right]
\end{aligned}
$$

with $k, l=1,2 ; k \neq l$. It is easy to see that agents prefer candidates of their own type. Using the notion of intermediate preferences,${ }^{24}$ we conclude that the pair $\left(\theta_{1}^{*}, \theta_{2}^{*}\right)=\left(m_{1}, m_{2}\right)$ is majority preferred to any other possible alternative. The vector of public goods can thereby be summarized as follows:

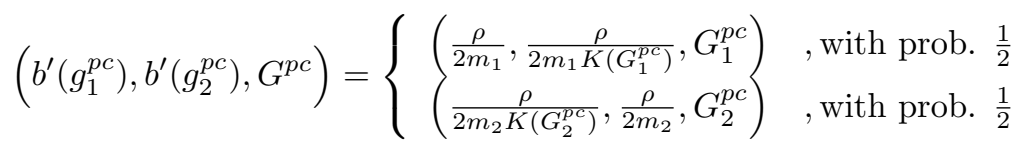

where $G_{k}$ is the solution to:

$$
m_{k} b\left(g_{l}^{p c}\right) \cdot K^{\prime}\left(G_{k}^{p c}\right)=\frac{\gamma}{2}, k \neq l
$$

This result reflects the two drawbacks of the centralized system pointed out in Besley and Coate (2003): uncertainty, as the identity of the minimum winning coalition is unknown a priori, and misallocation, since the provision is skewed towards those inside the coalition. In this context, however, both these properties of the centralized system are endowed with an extra dimension as compared to the exogenous spillovers framework. First, as now spillovers are set by the appointed legislator, they are also subject to uncertainty, just as in the decentralized case. Second, contrary to the standard approach, here the policymaker will take advantage of the interaction between local public goods and spillovers exclusively to his own benefit, which may induce a larger misallocation effect, particularly if the preferences of the legislator do not correspond to the interests of the society. As we explore further below, this last effect may or may not overcome the gain induced by an extra degree of freedom gained by considering endogenous spillovers.

Notice also that both uncertainty and misallocation remain present even if preferences are perfectly homogeneous. However, as preferences become farther apart, these problems tend to get worse, as there is a higher disparity between the preferred levels of $\left(g_{1}, g_{2}, G\right)$ by the two legislators.

\subsection{Centralization vs decentralization: a brief discussion}

A first consequence of this approach is that the optimal level of surplus is never attained. By observing the final allocations, it is immediate that the decentralized regime would attain a solution close to the welfare maximizing outcome if

\footnotetext{
${ }^{24}$ In the appendix we prove that $E W_{k}^{\theta}\left(\theta_{k}, \theta_{l}\right)$ can be written as intermediate preferences.
} 
spillovers are extremely low, which is true if the marginal cost of the national public good is high. In this case, the uncertainty problem would tend to vanish, and the main cost of the decentralized regime, which lies on the fact that policymakers ignore the spillover effect that the local public good in their jurisdiction might have on the neighbor district, would be naturally reduced. ${ }^{25}$ Meanwhile, in the centralized regime, both misallocation and uncertainty would be at their worst, since the formation of a low level of spillovers would imply a large provision of the local public good in the jurisdiction of the agenda setter, but a negligible provision on the other district.

On the other hand, the centralized system would be closer to obtain the maximal level of surplus if preferences are close to each other and the marginal cost of the national public good is low. These two requisites attenuate both uncertainty and misallocation, which characterize the centralized regime. In this case, the agenda setter would consider the implementation of a high amount of spillovers, providing a level of local public goods in the other jurisdiction close to the one in his own jurisdiction. However, the decentralized regime would be far from obtaining the surplus yielded by the centralized system, as local policy-makers would not take into account the possible benefits from these low cost spillovers when deciding how much local public good to provide in their jurisdictions. As preferences become farther apart, the uncertainty problem starts playing a more active role, deviating both systems from the optimal allocation.

We summarize these findings in figure 3 , which lays ground to the discussion that follows.

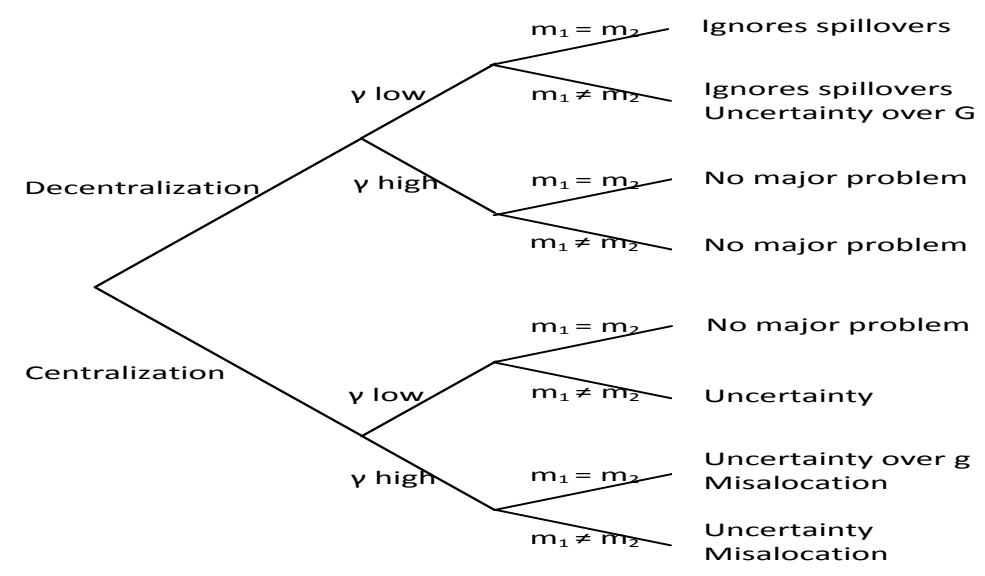

Figure 3: When uncertainty and misallocation play a significant role in public good provision.

Next, we put centralization against decentralization, separating the cases of homogeneous and heterogeneous preferences. In what follows, let $E W^{p c}$ and $E W^{p d}$ denote the expected welfare under centralization and decentralization

\footnotetext{
${ }^{25}$ Observe that, under heterogeneous preferences, although the provision of the national public good is still characterized by uncertainty, it tends to vanish as the marginal cost of providing it increases.
} 
respectively. $^{26}$

\subsubsection{Homogeneous preferences}

Consider that $m_{1}=m_{2}=m$. In this case, the uncertainty which characterizes spillovers vanishes, as the interests in the national legislature regarding the national public good become aligned. However, the local public good in the centralized system still presents both uncertainty and misallocation issues, which will drive us through our next result.

In order to keep things more concrete, let us for a moment interpret $G$ as the quality of a road network which connects two districts. In this stance, for a high value of $\gamma$, the members of the minimum winning coalition in a centralized regime simply realize that it is too expensive to enjoy local public goods that are not in their jurisdiction, as the cost of supplying a high quality infrastructure connecting both districts is fairly significative. Hence, the outcome in the centralized system will, to a great extent, disregard not only the jurisdiction unrepresented in the winning coalition, but also the infrastructures connecting both regions, letting them more isolated. The decentralized system, by assigning decision-making to different tiers of government, eliminates this problem of incentives, thereby deploying not only better infrastructures, but also an amount of local public goods more suited to the local context in the region left out of the winning coalition, yielding a higher welfare.

On the other hand, for low values of $\gamma$, the incentives of the minimum winning coalition in a centralized system become to some extent aligned with those of the society. As a result, the agenda setter supplies a higher level of amenities in the region unrepresented in the coalition, exploiting the benefits conveyed by them through a high quality road connection. In the decentralized system, as it does not allow the internalization of these low cost spillovers, the supply of local public goods only takes into account the benefits generated within the region where they are provided. Consequently, the delegate in the national legislature does not find worthwhile to supply such infrastructure, as he takes the provision of the local public goods for granted and cannot influence it. Therefore, our next result comes with no surprise.

Proposition 4. Suppose districts are homogeneous. Then, for low values of $\gamma$, centralization dominates decentralization, while, for high values of $\gamma$, decentralization achieves a higher welfare.

Observe that proposition 4 does not assure the existence of a unique cutoff value for $\gamma$ which unequivocally separates both systems, which contrasts with the standard approach and with the decentralization theorems presented in the literature. The reason is that $E W^{p c}-E W^{p d}$ is not necessarily monotone in $\gamma$, which limits what can be said about uniqueness of the cutoff. Intuitively, when the cost of spillovers is low, the expected welfare under centralization responds quicker to increases in $\gamma$ than decentralization, as the policy-maker can undertake a combined reduction in the supply of the relevant local public good and in the national public good. This implies that it is not necessary to have a very large marginal cost in order for the policy-maker in a centralized system to realize that it does not worth to supply relevant levels of the national public

\footnotetext{
${ }^{26}$ Dependence of exogenous parameters is suppressed for convenience.
} 
good, since the relative benefit for him becomes small very fast. On the contrary, decentralization responds in a more uniform fashion to changes in $\gamma$, since the supply of local public goods is fixed by local governments. Consequently, the difference in expected welfare, $E W^{p c}-E W^{p d}$, is not necessarily monotone for relatively large values of $\gamma$, since in this region $E W^{p d}$ is more responsive to small changes in the marginal cost of spillovers than $E W^{p c} .^{27}$

To wrap up, if preferences are homogeneous, centralization seems to do a better job if the cost of spillovers is low, since both the uncertainty and misallocation features that characterize the centralized system tend to vanish. On the other hand, high marginal costs in the provision of national public goods gives raise to uncertainty and misallocation issues in the centralized regime, motivated by the selfishness of the minimum winning coalition, while minimizing the problems generated by non-internalization of spillovers in the decentralized regime. Hence, decision-making based on local wishes should be put first.

\subsubsection{Heterogeneous preferences}

Under heterogeneous preferences the incentives of the legislator in a centralized system are never aligned with those of the society. For high values of $\gamma$, the decentralized system is able not only to better adapt the supply of public goods to local needs, but also to solve the selfish incentives of the minimum winning coalition that lead to uncertainty and misallocation in a centralized regime. Consequently, decentralization allows a more adequate provision of local public goods in the region unrepresented in the legislature, which would otherwise be forgotten by the winning coalition in the centralized system. However, as the marginal cost of the national public good becomes lower, the outcome is driven by a complex interaction between the costs and benefits of each system. On one side, the decentralized system ignores spillovers and is not able to solve the uncertainty problem that characterizes the provision of the national public good. On the other side, centralization not only induces uncertainty over the triplet $\left(g_{1}^{p c}, g_{2}^{p c}, G^{p c}\right)$, but also completely ignores the preferences of the jurisdiction whose legislator does not belong to the winning coalition. This discussion can be settled in the following decentralization theorem for a non-cooperative legislature:

Proposition 5. Suppose districts have distinct preferences. Then decentralization dominates centralization except, possibly, for low values of $\gamma$.

This result contrasts with the standard approach, where centralization was perceived as better under homogeneous preferences and could not be ruled out under heterogeneous preferences. Driving this result is the fact that, under the standard approach, the policy-maker in a centralized system would set the vector $\left(g_{1}, g_{2}, G\right)$ to the benefit of the society, enhancing the case for centralization, while under a non-cooperative legislature with no separation of powers the legislator in a centralized system sets the levels of local public goods and the amount of spillovers to his own benefit. Hence, decentralization can be seen as a way to go around this problem of incentives created in the centralized system, as it allows separation of powers among different tiers of government.

\footnotetext{
${ }^{27}$ However, our numerical results with many distinct specifications and parameter values show that, although monotonicity is in fact a very weak condition in this context, the existence of a unique cutoff is much easier to guarantee.
} 
It should be noted, however, that the above results cannot be compared with those presented in the literature, namely in Besley and Coate (2003). The possible inexistence of a cutoff that separates both systems is not due so much to the effect of endogenous spillovers, but to the fact that we have assumed a more general specification for the function $b(g)$. We discuss the impact of endogenous spillovers below.

\section{Example (revisited)}

We now take back the same example introduced previously in the standard approach. ${ }^{28}$ Figure 4 plots the difference in welfare between centralization and decentralization, illustrating the results above. ${ }^{29}$

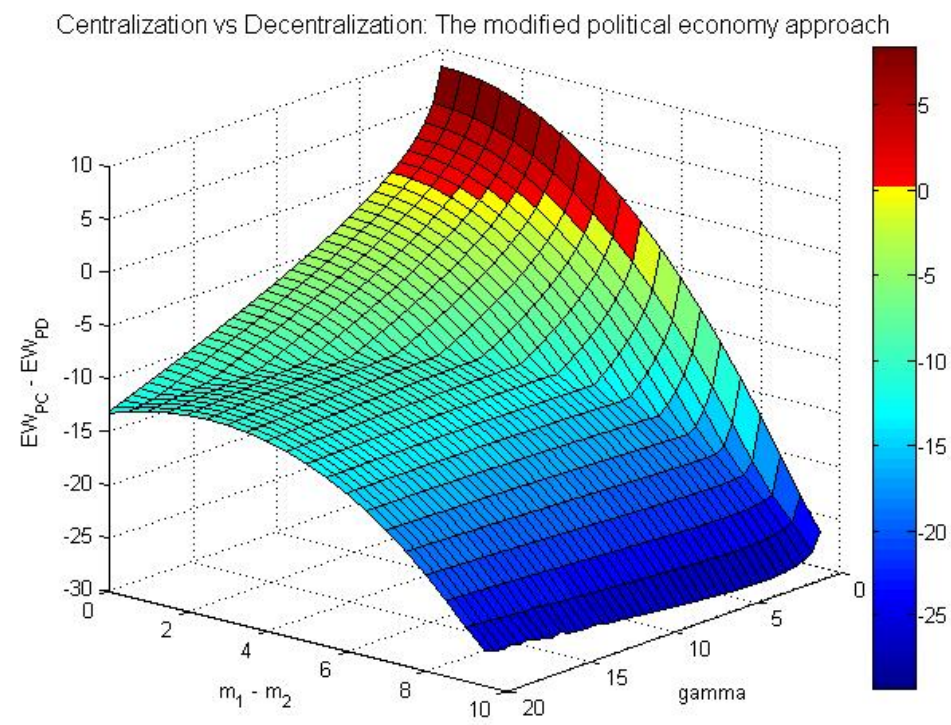

Figure 4: Difference in welfare between centralization and decentralization.

Note that the set of parameters for which centralization outperforms decentralization is very restricted. Only if preferences are not significantly heterogeneous and the cost of the national public good is low, which implies that the political decisions of the winning coalition in a centralized regime are, to some extent, aligned with those of the unrepresented region, centralization can be regarded as a better option. Otherwise, the interests of the region which does

\footnotetext{
${ }^{28}$ Recall that:
}

$$
b\left(g_{k}\right)=g_{k}^{0.5} \text { and } K(G)=\frac{G^{0.5}}{G^{0.5}+1}
$$

with $\rho=1$ and $\bar{m}=5$.

${ }^{29}$ The conclusions we draw, as well as the inexistence of more than one cutoff, are extremely robust to different specifications and parameter values. However, the monotonicity condition can be easily broken for large values of $\gamma$, in the region where decentralization dominates centralization. 
not take part in the coalition may be so severely affected that decentralization clearly outperforms the centralization. Intuitively, decentralization may simply pen up the selfish interests of the agenda setter, avoiding the deployment of a mix of local public goods and spillovers that clearly prejudices the interests of the society by transferring local public good decision-making to local authorities, thus eliminating the misallocation effect. This feature, which gains particular strength when preferences across jurisdiction are somewhat heterogeneous, implies that the existence of a threshold for $\gamma$ which assures the domination of one system over the other is not assured. The forces at interaction here may simply shed some light on the reasons why some regions seek to decentralize political decision-making, but find unbreakable barriers by the policy-makers in power.

\subsection{A comment on endogenous spillovers}

Given the previous discussion, it seems that no direct conclusion can be undertaken when we compare an economy with endogenous spillovers with another similar economy, but where spillovers are exogenously set. In fact, while, in the present, centralization allows policy-makers to play with the interaction between local public goods and spillovers to achieve higher levels of welfare, as they have one extra degree of freedom in their choice set - endogenous spillover effect-, this advantage is mostly used by the agenda setter to turn the game into his favor, increasing the welfare in his jurisdiction at the expense of the other jurisdiction - misallocation effect. The balance of these two effects dictates the final outcome:

Proposition 6. Introducing endogenous spillovers has an ambiguous impact on the trade-off between centralization and decentralization. The endogenous spillover effect creates a bias towards centralization, whereas the misallocation effect creates a bias against centralization.

This result can be better illustrated with an example.

\section{Example (continued)}

Contrary to the previous illustrations, small changes in the parameters of the model may have significant consequences on the conclusions we are able to extract. In order to capture the main dynamic brought in by introducing endogenous spillovers, we will consider three different cases, each representing one possible outcome from proposition 6 . The functional form is:

$$
b\left(g_{k}\right)=g_{k}^{\alpha} \quad \text { and } \quad K(G)=\frac{G^{0.5}}{G^{0.5}+1},
$$

but now $\alpha$ will be allowed to take three different values, $\alpha=\{0.4 ; 0.55 ; 0.7\}$. Again, we set $\rho=1$ and $\bar{m}=5$. The outcomes are illustrated in figures 5 7. The important lines to retain from these figures are the zero-contour lines, which represent, for each value of $m_{1}-m_{2}$, the cutoff $\widehat{\gamma}$, if exists, that makes the expected welfare under both systems coincide. Along the lines of the above discussion, observe that the existence of this cutoff is not assured for large values of $m_{1}-m_{2}$, even when exogenous spillovers are considered. ${ }^{30}$

\footnotetext{
${ }^{30}$ These plots were built following exactly the steps used to prove proposition 6 , which can be found in the appendix.
} 


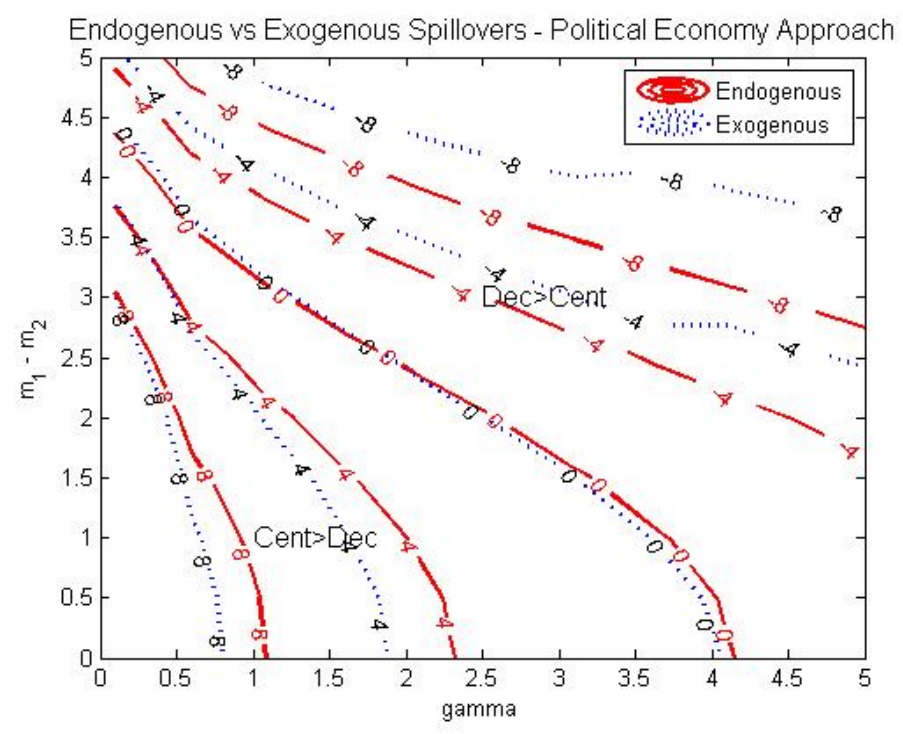

Figure 5: Contour lines of the difference in welfare between centralization and decentralization, for the case of endogenous and exogenous spillovers, $\alpha=0.55$.

The most interesting situation occurs, perhaps, in figure 5. Here, if preferences across jurisdictions are similar, the cutoff point where the welfare under both systems coincide is slightly increased for the case of endogenous spillovers, meaning that the policy-maker in a centralized system is able to extract some benefits of the interaction between national and local public goods in favor of the society, as both objectives are, to some extent, aligned. In this range, the endogenous spillover effect dominates the misallocation effect. If preferences become significantly heterogenous, the gain induced by endogenous spillovers is not enough to compensate the higher incentives of the policy-maker in a centralized system to shape the vector $\left(g_{1}, g_{2}, G\right)$ to his image, and so the trade-off is changed in favor of decentralizarion. This illustrates the misallocation effect in action.

Figure 6 illustrates two alternative outcomes. On the left, the misallocation effect always dominates, as the costs imposed on the society by the agenda setter under centralization are sufficient to overcome the gains from the interplay between the vertical and the horizontal dimensions in the provision of public goods brought in by the endogenous spillover setup. This implies that, for any value of $\widehat{\gamma}$ such that exogenous spillovers originates the same expected welfare for both systems, introducing endogenous spillovers shifts the relative performance towards the decentralized regime. On the right, on the other hand, the agenda setter in a centralized regime and in an endogenous spillover framework is able to improve the level of welfare in the society as compared to the exogenous spillover setup. To see this, observe that, for all points such that exogenous spillovers originate identical levels of welfare under both systems, endogenous spillovers are yielding a positive bias towards centralization. This is due to the endogenous spillover effect, which, in this case, is taking the utmost advantage of the above 

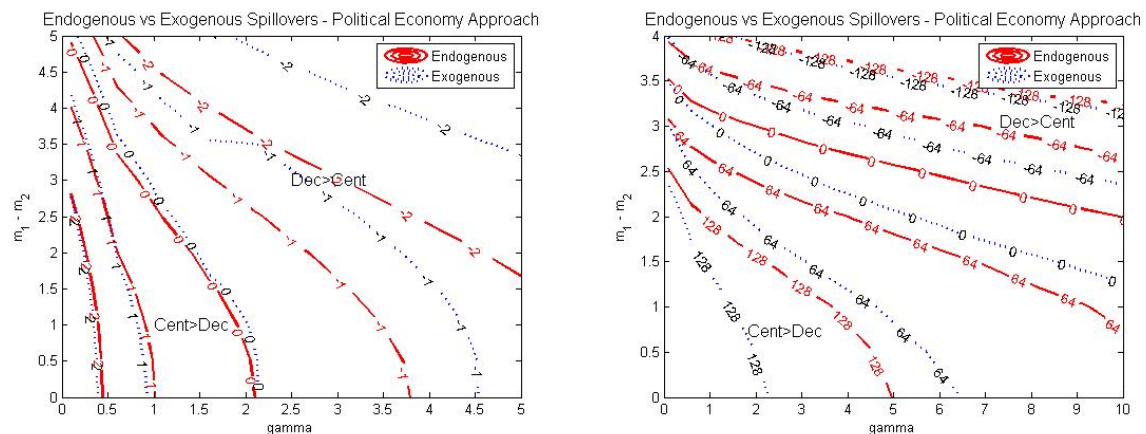

Figure 6: Contour lines of the difference in welfare between centralization and decentralization. On the left, $\alpha=0.4$; on the right, $\alpha=0.7$.

mentioned interplay between vertically and horizontally provided public goods that is possible under this new setup to improve the case for centralization.

\section{Centralization with separation of powers}

It has been recognized in the literature that the minimum winning coalition view of legislative decision-making is the exception rather than the rule (Besley and Coate, 2003). In reality, most economies organize decision-making under less radical decision rules, which usually do imply some sort of separation of powers among the distinct members that compose the legislature. In this section, we analyze an alternative approach to decision-making, in which different legislators are responsible for setting vertically distinct policy vectors. In other words, we consider that the supply of local public goods will be set by one of the members of the legislature, while the level of spillovers will be defined by the other, bringing our analysis closer to the realm of most legislatures.

\subsection{Policy determination}

More specifically, let the type of the elected legislator in jurisdiction $k$ in stage 1 be given by $\theta_{k}, k=1,2$. In stage 2 , one of the legislators, say type $\theta_{k}$ (henceforth local committee), is randomly selected by nature to set the supply of both local public goods, while the other legislator, say type $\theta_{l}$ (henceforth national committee), will be responsible for defining the level of spillovers separation of powers at the central level. The rules for decentralization do not change.

The type $\theta_{k}$ legislator will now solve:

$$
\max _{g_{k}, g_{l}} \theta_{k}\left[b\left(g_{k}\right)+K(G) \cdot b\left(g_{l}\right)\right]-\rho \frac{g_{k}+g_{l}}{2}-\frac{\gamma}{2} G ; k \neq l
$$

which solution yields: 


$$
\begin{aligned}
b^{\prime}\left(g_{k}\left(\theta_{k}\right)\right) & =\frac{\rho}{2 \theta_{k}} \\
b^{\prime}\left(g_{l}\left(\theta_{k}, G\right)\right) & =\frac{\rho}{2 \theta_{k} K(G)}
\end{aligned}
$$

Note that the legislator will not be anymore able to take into account the interaction between local and national public goods, since decisions are now taken by different committees. Simultaneously, the type $\theta_{l}$ legislator sets $G$ such that:

or,

$$
G=\arg \max _{G} \theta_{l}\left[b\left(g_{l}\right)+K(G) \cdot b\left(g_{k}\right)\right]-\rho \frac{g_{k}+g_{l}}{2}-\frac{\gamma}{2} G ; k \neq l
$$

$$
\theta_{l} b\left(g_{k}\right) \cdot K^{\prime}\left(G\left(\theta_{l}\right)\right)=\frac{\gamma}{2}
$$

Again, the median voter is pivotal in each jurisdiction, ${ }^{31}$ and so the implemented vector of public goods is:

$$
\left(b^{\prime}\left(g_{1}^{p c s}\right), b^{\prime}\left(g_{2}^{p c s}\right), G^{p c s}\right)= \begin{cases}\left(\frac{\rho}{2 m_{1}}, \frac{\rho}{2 m_{1} K\left(G_{1}^{p c s}\right)}, G_{1,2}^{p c s}\right) & \text { with prob. } \frac{1}{2} \\ \left.\frac{\rho}{2 m_{2} K\left(G_{2}^{p c s}\right)}, \frac{\rho}{2 m_{2}}, G_{2,1}^{p c s}\right) & \text { with prob. } \frac{1}{2}\end{cases}
$$

where $G_{k, l}^{p c s}$ is defined implicitly by: ${ }^{32}$

$$
m_{l} b\left(g_{k}^{p c s}\right) \cdot K^{\prime}\left(G_{k, l}^{p c s}\right)=\frac{\gamma}{2}, k \neq l
$$

\subsection{The effects of separation of powers}

Again, we can identify the two drawbacks of a centralized system: uncertainty and misallocation. However, the provision of the national public good is undertaken by the median voter belonging to a different jurisdiction than the one who set the supply of local public goods. This implies that, although the provision rules for local public goods are the same as in the centralized system with no separation of powers, the final allocations will be different. In fact, each of the two vertical levels that compose the choice of public goods (local and national) is represented by distinct preferences, since the decisions at each level are a responsibility of distinct entities.

In order to illustrate the consequences of this approach, throughout the remaining analysis we will work with the following familiar specification for the benefit from local public goods, which greatly simplifies the algebra:

$$
b(g)=g^{0.5}
$$

No restriction on $K(G)$ is necessary, besides those presented before. Under this specification, the following result can be derived:

\footnotetext{
${ }^{31}$ Writing the expected surplus of a type $\theta$ citizen in district $k$, and applying the concept of intermediate preferences, the result follows immediately.

${ }^{32}$ The first subscript denotes the jurisdiction to where the members of the local committee belong, while the second subscript denotes the jurisdiction of the members of the national committee.
} 
Proposition 7. A centralized system with separation of powers delivers a higher expected welfare as compared with an identical system with no separation of powers.

In order to understand this result, recall that, in a centralized regime with no separation of powers, the agenda setter chooses the whole policy vector $\left(g_{1}, g_{2}, G\right)$ to maximize his own utility, completely ignoring the preferences of the other member in the legislature. This not only imposes a large misallocation cost, but also a high level of uncertainty, since the allocations tend to be more extreme, specially when the cost of the national public good is high. If the allocative powers in the society are distributed among the members of the legislature, the local committee looses one degree of freedom to the national committee, who will take advantage of it to set a level of spillovers more appropriate to its true preferences. In this way, the expropriation that the members of the local committee are able to undertake becomes limited, misallocation and uncertainty are reduced, and expected welfare increases. An immediate corollary emerges from this discussion:

Corollary 1. With separation of powers, the set of parameters $\left(m_{1}, m_{2}, \rho, \gamma\right)$ for which centralization dominates decentralization is increased as compared to the case of no separation of powers.

Proof. Obvious, following proposition 7.

This result is a direct consequence of proposition 7. While, in a decentralized regime, no vertical strategic interaction is taken into account, a centralized regime, even with separation of powers, is able consider the vertical interactions between local and national public goods, while not allowing uncertainty and misallocation to attain the levels that characterized the non-cooperative legislature with no separation of powers. Note that what induces an organizational system to integrate vertical interactions is not so much the concentration of decision-making on a unique source, but mainly the internalization of spillovers, since this is enough to create a strategic interaction between the members of the different committees. This is why the decentralized regime fails to consider these interactions, while a centralized regime is always able to take some advantage of them.

However, in spite of this shift in favor of a centralized system, all decentralization theorems presented in the previous section remain valid. As both misallocation and uncertainty do not vanish, but are just attenuated, propositions 4 and 5 still hold, although the range of $\gamma$ for which centralization is better than decentralization is extended. In particular observe that, if preferences are heterogeneous, the members of the local committee still impose a large cost on the society, by setting a supply of local public goods which does not match the preferences of the members in the national committee. The best that the members of this committee can do is to attenuate this effect, by using the national public good to appropriate some benefits from the local public good in the jurisdiction represented by the members of the local committee, but this may not suffice to dictate a superior performance of a centralized system against a decentralized one.

It is, however, sufficient to dictate an improvement in the case for centralization, when we compare with the traditional exogenous spillover assumption. That is: 
Proposition 8. Endogenous spillovers, when compared against exogenous spillovers, never improve the case for decentralization when the alternative is centralization with separation of powers.

Intuitively, separation of powers decreases substantially the misallocation effect identified in the previous section, making a case for endogenous spillovers. In fact, if we take into account the actions undertaken by the local committee, taking spillovers as given, the misallocation effect is the same both with exogenous and endogenous spillovers. But, contrary to the case with no separation of powers, once we consider the decisions of the national committee, we are able to create an endogenous spillover effect, resulting from the vertical interactions between local and national public goods, while not allowing an increase in the misallocation effect, since separation of powers prevents this from happening.

\section{Example (revisited)}

Let us again consider the same illustration of previous sections, with:

$$
b\left(g_{k}\right)=g_{k}^{0.5} \quad \text { and } \quad K(G)=\frac{G^{0.5}}{G^{0.5}+1}
$$

Figure 7 plots the contour lines of $E W^{p c}-E W^{p d}$ and $E W^{p c s}-E W^{p d}$, illustrating both proposition 7 and corollary 1 . The former implies that, for all contour lines such that the case of no separation of powers yields a difference in the expected welfare of $E W^{p c}-E W^{p d}=w$, the case of separation of powers originates a difference of $E W^{p c s}-E W^{p d} \geq w{ }^{33}$ The second is a direct application of the first, but with $w=0$.

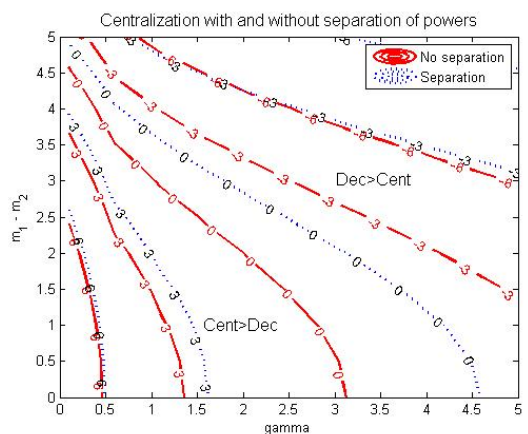

Figure 7: Contour lines of the difference in welfare between centralization and decentralization, considering the cases of separation and no separation of powers.

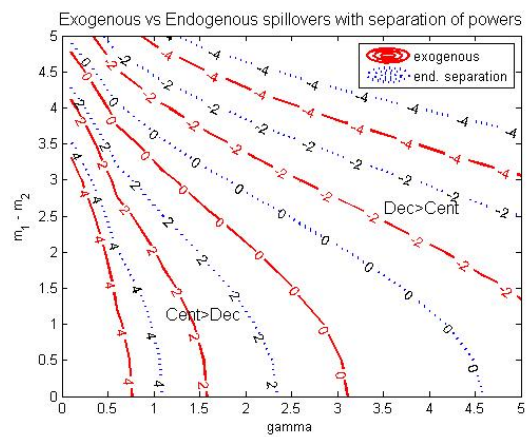

Figure 8: Contour lines of the difference in welfare between centralization with separation of powers and decentralization, for the cases of endogenous and exogenous spillovers.

Figure 8 plots the contour lines for exogenous and endogenous spillovers. When compared to the case of exogenous spillovers, endogenous spillovers provide a shift in the space of parameters for which centralization outperforms decentralization.

\footnotetext{
${ }^{33} E W^{p c s}$ denotes the expected welfare in a non-cooperative legislature with separation of powers. The remaining notation was presented previously.
} 
A centralized system with this characteristics can take into account, to some extent, the vertical interactions between public goods provided at different levels of government, while preventing an excessive appropriation of surplus by some members of the legislature, while decentralization, due to its characteristics, is not able benefit from this vertical integration. However, decentralization can still dominate, particularly if preferences are significantly heterogeneous, a case in which adapting local public goods to the regional context is more relevant than any vertical interaction that centralization might be able to integrate.

\section{Conclusion}

This paper was a first attempt to integrate vertical interactions between public goods with distinct spacial characteristics, in a very familiar context: the tradeoff between centralized and decentralized provision of local public goods. We showed, in a framework where the level of spillovers is endogenous and depends on the provision of a national public good, that different organizational system integrate these vertical interactions differently (or not at all), consequently affecting the decentralization theorems that we know from the literature. We also illustrated the major changes of this approach as compared to the usual specification of exogenous spillovers, and presented a new non-cooperative legislature with separation of powers at the central level that is able to deliver a better relative performance of the centralized system as compared to the more common case of no separation of powers.

Much is left to be done, however, not only in a context of decentralization, but also in many other areas, where different types of public goods with distinct spacial characteristics (e.g., local, regional and national) do not interact only at the horizontal level (same characteristics), but also at the vertical level (different characteristics). This interactions may reveal new interesting insights, for example, in topics like federal systems, or on the number and size of nations. 


\section{References}

N. Akai and K. Mikami. Fiscal decentralization and centralization under a majority rule: a normative analysis. Economic Systems, 30(1):41-55, 2006.

D.P. Baron and J. Ferejohn. Bargaining in legislatures. American Political Science Review, 83:1181-1206, 1989.

T. Besley and S. Coate. An economic model of representative democracy. The Quarterly Journal of Economics, 112(1):85-114, 1997.

T. Besley and S. Coate. Centralized versus decentralized provision of local public goods: a political economy approach. Journal of Public Economics, 87(12): 2611-2637, 2003.

F. Bloch and U. Zenginobuz. The effect of spillovers on the provision of local public goods. Review of Economic Design, 11(3):199-216, 2007.

P. Bolton and G. Roland. The breakup of nations: A political economy analysis. The Quarterly Journal of Economics, 112(4):1057-1090, 1997.

G. Cheikbossian. Federalism, distributive politics and representative democracy. Economics of Governance, 1(2):105-122, 2000.

R. Dur and H. Roelfsema. Why does centralization fail to internalise policy externalities? Public Choice, 122:395-416, 2005.

S. Goyal and K. Staal. The political economy of regionalism. European Economic Review, (48):563-593, 2004.

O. Koppel. Reviewing Oates' insights in a repeated game setting. Economics of Governance, 6:229-243, 2005.

B. Lockwood. Distributive politics and the costs of centralization. The Review of Economic Studies, 69(2):313-337, 2002.

B. Lockwood. Fiscal decentralization: a political economy perspective. In: The Handbook of Fiscal Federalism (ed. E. Ahmad and G. Brosio), Edward Elgar Press, 2006.

W. Oates. Fiscal Federalism. Harcourt Brace, New York, 1972.

M.J. Osborne and Al Slivinski. A model of political competition with citizencandidates. The Quarterly Journal of Economics, 111(1):65-96, 1996.

U. Panizza. On the determinants of fiscal centralization: theory and evidence. Journal of Public Economics, 74:97-139, 1999.

M. Redoano and K.A. Scharf. The political economy of policy centralization: direct versus representative democracy. Journal of Public Economics, 88: 799-817, 2004.

J. Schnellenbach, L. Feld, and C. Schaltegger. The impact of referendums on the centralisation of public goods provision - a political economy approach. University of Heidelberg Discussion Paper Series, No. 440, 2007. 
C.M. Tiebout. A pure theory of local expenditures. The Journal of Political Economy, 64(5):416-424, 1956.

A. Williams. The optimal provision of public goods in a system of local government. The Journal of Political Economy, 74(1):18-33, 1966. 


\section{Appendix}

\section{A Notation}

\section{A.1 Common notation used in the proofs of propositions 1,2 and 3}

Let $\boldsymbol{\vartheta}=(\varrho, \gamma)$ denote the vector of exogenous parameters, with $\varrho=\left(m_{1}, m_{2}, \rho\right)$. Hence, the vector of public good allocations under decentralization, represented in equations (5) and (6), can be written as $\left(g_{1}^{d}(\varrho), g_{2}^{d}(\varrho), G^{d}(\boldsymbol{\vartheta})\right)$ while, in a centralized system, the outcomes in (7) and (8) can be summarized as $\left(g_{1}^{c}(\boldsymbol{\vartheta}), g_{2}^{c}(\boldsymbol{\vartheta}), G^{c}(\boldsymbol{\vartheta})\right)$. Using this notation, the maximum level of surplus attained under each system is:

$$
\begin{aligned}
W^{d}(\boldsymbol{\vartheta}) & =m_{1}\left[b\left(g_{1}^{d}(\varrho)\right)+K\left(G^{d}(\boldsymbol{\vartheta})\right) \cdot b\left(g_{2}^{d}(\boldsymbol{\varrho})\right)\right]+ \\
& +m_{2}\left[b\left(g_{2}^{d}(\varrho)\right)+K\left(G^{d}(\boldsymbol{\vartheta})\right) \cdot b\left(g_{1}^{d}(\boldsymbol{\varrho})\right)\right]- \\
& -\rho\left[g_{1}^{d}(\varrho)+g_{2}^{d}(\varrho)\right]-\gamma G^{d}(\boldsymbol{\vartheta})
\end{aligned}
$$

for decentralization, and:

$$
W^{c}(\boldsymbol{\vartheta})=2 \bar{m} \cdot\left[1+K\left(G^{c}(\boldsymbol{\vartheta})\right)\right] \cdot b\left(g^{c}(\boldsymbol{\vartheta})\right)-2 \rho g^{c}(\boldsymbol{\vartheta})-\gamma G^{c}(\boldsymbol{\vartheta})
$$

for centralization.

Similarly, the allocations for the optimal outcome can be written as $\left(g_{1}^{o}(\boldsymbol{\vartheta}), g_{2}^{o}(\boldsymbol{\vartheta}), G^{o}(\boldsymbol{\vartheta})\right)$, and the welfare is:

$$
\begin{aligned}
W^{o}(\boldsymbol{\vartheta}) & =\left[m_{1}+m_{2} K\left(G^{o}(\boldsymbol{\vartheta})\right)\right] \cdot b\left(g_{1}^{o}(\boldsymbol{\vartheta})\right)+ \\
& +\left[m_{2}+m_{1} K\left(G^{o}(\boldsymbol{\vartheta})\right)\right] \cdot b\left(g_{2}^{o}(\boldsymbol{\vartheta})\right)- \\
& -\rho\left[g_{1}^{o}(\boldsymbol{\vartheta})+g_{2}^{o}(\boldsymbol{\vartheta})\right]-\gamma G^{o}(\boldsymbol{\vartheta})
\end{aligned}
$$

\section{A.2 Common notation used in the proofs of propositions 4,5 and 6}

Again, let $\boldsymbol{\vartheta}=(\varrho, \gamma)$ denote the vector of exogenous parameters, with $\varrho=$ $\left(m_{1}, m_{2}, \rho\right)$. The term $W^{o}(\boldsymbol{\vartheta})$ will be as defined above. The vector of public good allocations under decentralization is denoted by $\left(g_{1}^{p d}(\varrho), g_{2}^{p d}(\varrho), G_{k}^{p d}(\boldsymbol{\vartheta})\right)$ if $k$ is chosen as the agenda setter in the national legislature. This implies an expected welfare of:

$$
E W^{p d}(\boldsymbol{\vartheta})=\frac{1}{2}\left[W_{1,1}^{p d}(\boldsymbol{\vartheta})+W_{2,1}^{p d}(\boldsymbol{\vartheta})+W_{1,2}^{p d}(\boldsymbol{\vartheta})+W_{2,2}^{p d}(\boldsymbol{\vartheta})\right]
$$

where $W_{1, k}^{p d}(\boldsymbol{\vartheta})$ and $W_{2, k}^{p d}(\boldsymbol{\vartheta})$ are respectively the welfare in jurisdictions 1 and 2 if the policy-maker in $k$ is appointed as the agenda setter in the national legislature, i.e. 


$$
\begin{aligned}
W_{1, k}^{p d}(\boldsymbol{\vartheta}) & =m_{1}\left[b\left(g_{1}^{p d}(\varrho)\right)+K\left(G_{k}^{p d}(\boldsymbol{\vartheta})\right) \cdot b\left(g_{2}^{p d}(\varrho)\right)\right]-\rho g_{1}^{p d}(\varrho)-\frac{\gamma}{2} G_{k}^{p d}(\boldsymbol{\vartheta}) \\
W_{2, k}^{p d}(\boldsymbol{\vartheta}) & =m_{2}\left[b\left(g_{2}^{p d}(\varrho)\right)+K\left(G_{k}^{p d}(\boldsymbol{\vartheta})\right) \cdot b\left(g_{1}^{p d}(\boldsymbol{\varrho})\right)\right]-\rho g_{2}^{p d}(\varrho)-\frac{\gamma}{2} G_{k}^{p d}(\boldsymbol{\vartheta})
\end{aligned}
$$

Under centralization, public good allocations are defined by $\left(g_{k, k}^{p c}(\boldsymbol{\vartheta}), g_{l, k}^{p c}(\boldsymbol{\vartheta}), G_{k}^{p c}(\boldsymbol{\vartheta})\right)$, where the first index in local public goods denotes the region to which it concerns, and the second index denotes the jurisdiction of the agenda setter, $k$, with $k, l=1,2 ; k \neq l$. The expected welfare is:

$$
E W^{p c}(\boldsymbol{\vartheta})=\frac{1}{2}\left[W_{1,1}^{p c}(\boldsymbol{\vartheta})+W_{2,1}^{p c}(\boldsymbol{\vartheta})+W_{2,1}^{p c}(\boldsymbol{\vartheta})+W_{2,2}^{p c}(\boldsymbol{\vartheta})\right]
$$

where $W_{1, k}^{p c}(\boldsymbol{\vartheta})$ and $W_{2, k}^{p c}(\boldsymbol{\vartheta})$ are respectively the welfare in jurisdictions 1 and 2 if the policy-maker in $k$ is appointed as the agenda setter, i.e.:

$$
\begin{aligned}
W_{1, k}^{p c}(\boldsymbol{\vartheta}) & =m_{1}\left[b\left(g_{1, k}^{p c}(\boldsymbol{\vartheta})\right)+K\left(G_{k}^{p c}(\boldsymbol{\vartheta})\right) \cdot b\left(g_{2, k}^{p c}(\boldsymbol{\vartheta})\right)\right]- \\
& -\frac{\rho}{2}\left(g_{1, k}^{p c}(\boldsymbol{\vartheta})+g_{2, k}^{p c}(\boldsymbol{\vartheta})\right)-\frac{\gamma}{2} G_{k}^{p c}(\boldsymbol{\vartheta}) \\
W_{2, k}^{p c}(\boldsymbol{\vartheta}) & =m_{2}\left[b\left(g_{2, k}^{p c}(\boldsymbol{\vartheta})\right)+K\left(G_{k}^{p c}(\boldsymbol{\vartheta})\right) \cdot b\left(g_{1, k}^{p c}(\boldsymbol{\vartheta})\right)\right]- \\
& -\frac{\rho}{2}\left(g_{1, k}^{p c}(\boldsymbol{\vartheta})+g_{2, k}^{p c}(\boldsymbol{\vartheta})\right)-\frac{\gamma}{2} G_{k}^{p c}(\boldsymbol{\vartheta})
\end{aligned}
$$

\section{B Proof of results}

\section{B.1 Proof of proposition 1}

We divide the proof in two claims.

Claim 1. Decentralization produces a lower surplus than optimal.

Proof. First of all, note that $g_{k}^{o}(\boldsymbol{\varrho}, \gamma)>g_{k}^{d}(\boldsymbol{\varrho})$, for $k=1,2$, and $G^{o}(\varrho, \gamma)>$ $G^{d}(\varrho, \gamma), \forall \gamma$. The first relationship is immediate from comparing equations (2) and (3) with (5); the second can be obtained from (4) and (7), after observing that:

$$
m_{1} b\left(g_{2}^{d}(\boldsymbol{\varrho})\right)+m_{2} b\left(g_{1}^{d}(\boldsymbol{\varrho})\right)<m_{1} b\left(g_{2}^{o}(\boldsymbol{\varrho}, \gamma)\right)+m_{2} b\left(g_{1}^{o}(\boldsymbol{\varrho}, \gamma)\right)
$$

implies $K^{\prime}\left(G^{o}(\varrho, \gamma)\right)<K^{\prime}\left(G^{d}(\varrho, \gamma)\right), \forall \gamma$, as $K^{\prime \prime}(G)<0$. Hence, the decentralized outcome produces a lower level of surplus than the optimal allocation.

Claim 2. Centralization attains the optimal level of surplus.

Proof. Let $m_{k}=m, k=1,2$. The optimal solution yields:

$$
b^{\prime}\left(g_{k}^{o}(\boldsymbol{\varrho}, \gamma)\right)=\frac{\rho}{m\left[1+K\left(G^{o}(\varrho, \gamma)\right)\right]} \quad \text { and } \quad m b\left(g^{o}(\boldsymbol{\varrho}, \gamma)\right) \cdot K^{\prime}\left(G^{o}(\boldsymbol{\varrho}, \gamma)\right)=\frac{\gamma}{2}
$$

which is also the solution of the centralized system with homogeneous preferences. Hence, the centralized system yields the maximum level of surplus.

From these two claims proposition 1 follows immediately. 


\section{B.2 Proof of proposition 2}

We begin by establishing two claims.

Claim 3. The difference in welfare between the two systems, $W^{c}(\varrho, \gamma)-W^{d}(\varrho, \gamma)$, is strictly decreasing in $\gamma$.

Proof. Differentiating $W^{c}(\varrho, \gamma)-W^{d}(\varrho, \gamma)$, we obtain:

$$
\begin{gathered}
\phi(\varrho, \gamma)=\frac{\mathrm{d}}{\mathrm{d} \gamma}\left[W^{c}(\boldsymbol{\varrho}, \gamma)-W^{d}(\boldsymbol{\varrho}, \gamma)\right]= \\
=\frac{\mathrm{d} W^{c}}{\mathrm{~d} g^{c}} \frac{\mathrm{d} g^{c}}{\mathrm{~d} \gamma}+\frac{\mathrm{d} W^{c}}{\mathrm{~d} G^{c}} \frac{\mathrm{d} G^{c}}{\mathrm{~d} \gamma}+\frac{\mathrm{d} W^{c}}{\mathrm{~d} \gamma}-\left[\frac{\mathrm{d} W^{d}}{\mathrm{~d} G^{d}} \frac{\mathrm{d} G^{d}}{\mathrm{~d} \gamma}+\frac{\mathrm{d} W^{d}}{\mathrm{~d} \gamma}\right]
\end{gathered}
$$
to:

By the envelope theorem, $\frac{d W^{c}}{d g^{c}}=\frac{d W^{c}}{d G^{c}}=\frac{d W^{d}}{d G^{d}}=0$. Hence, $\phi(\varrho, \gamma)$ reduces

$$
\phi(\boldsymbol{\varrho}, \gamma)=\frac{\mathrm{d} W^{c}}{\mathrm{~d} \gamma}-\frac{\mathrm{d} W^{d}}{\mathrm{~d} \gamma}=G^{d}(\boldsymbol{\varrho}, \gamma)-G^{c}(\boldsymbol{\varrho}, \gamma)
$$

We now prove that $G^{d}(\boldsymbol{\varrho}, \gamma)-G^{c}(\varrho, \gamma)<0, \forall \gamma$, with $b(g)=g^{0.5}$. Under this specification, the provision of local public goods under both systems becomes:

$$
\begin{aligned}
g^{c}(\varrho, \gamma) & =\left[\frac{\bar{m}\left[1+K\left(G^{c}(\varrho, \gamma)\right)\right]}{2 \rho}\right]^{2} \\
g_{k}^{d}(\varrho) & =\left[\frac{m_{k}}{2 \rho}\right]^{2}, k=1,2
\end{aligned}
$$

Making use of conditions (6) and (8), which give us the provision rules for the national public good $G$ for both systems, it is immediate to show that $G^{d}(\varrho, \gamma)-G^{c}(\varrho, \gamma)<0$ is equivalent to:

$$
\left(m_{1}+m_{2}\right) \cdot b\left(g^{c}(\boldsymbol{\varrho}, \gamma)\right)-\left[m_{1} b\left(g_{2}^{d}(\varrho)\right)+m_{2} b\left(g_{1}^{d}(\varrho)\right)\right]>0
$$

since $K^{\prime}(G)$ is decreasing in $G$. So, in order to reach a contradiction, suppose that:

$$
\left(m_{1}+m_{2}\right) \cdot b\left(g^{c}(\varrho, \gamma)\right)-\left[m_{1} b\left(g_{2}^{d}(\varrho)\right)+m_{2} b\left(g_{1}^{d}(\varrho)\right)\right] \leq 0,
$$

and consider the set of parameters $\left(m_{1}, m_{2}\right)$ that constitute any mean preserving spread of $\bar{m}$, such that $m_{1}=\bar{m}(1+\varepsilon)$ and $m_{2}=\bar{m}(1-\varepsilon), \varepsilon \in[0,1]$. Thus,

$$
\begin{aligned}
& \left(m_{1}+m_{2}\right) \cdot b\left(g^{c}(\varrho, \gamma)\right)-\left[m_{1} b\left(g_{2}^{d}(\varrho)\right)+m_{2} b\left(g_{1}^{d}(\varrho)\right)\right]= \\
= & m_{1}\left[b\left(g^{c}(\varrho, \gamma)\right)-b\left(g_{2}^{d}(\varrho)\right)\right]+m_{2}\left[b\left(g^{c}(\varrho, \gamma)\right)-b\left(g_{1}^{d}(\varrho)\right)\right]= \\
= & \frac{\bar{m}^{2}(1+\varepsilon)}{2 \rho}\left[K\left(G^{c}(\varrho, \gamma)\right)+\varepsilon\right]+\frac{\bar{m}^{2}(1-\varepsilon)}{2 \rho}\left[K\left(G^{c}(\varrho, \gamma)\right)-\varepsilon\right]= \\
= & \frac{\bar{m}^{2}}{\rho} K\left(G^{c}(\varrho, \gamma)\right)+\frac{\bar{m}^{2} \varepsilon^{2}}{\rho}= \\
= & \frac{\bar{m}^{2}}{\rho}\left[K\left(G^{c}(\varrho, \gamma)\right)+\varepsilon^{2}\right]>0
\end{aligned}
$$


A contradiction! Hence, $G^{d}(\varrho, \gamma)-G^{c}(\varrho, \gamma)<0, \forall \gamma$, and strict monotonicity follows.

Claim 4. Centralization dominates decentralization for low values of $\gamma$, while it is dominated for large values of $\gamma$.

Proof. It is obvious that

$$
\lim _{\gamma \rightarrow 0} W^{c}(\varrho, \gamma)=\lim _{\gamma \rightarrow 0} W^{o}(\varrho, \gamma)>\lim _{\gamma \rightarrow 0} W^{d}(\varrho, \gamma)
$$

as the allocations under a centralized regime converge to the optimal ones as $\gamma$ goes to zero. On the other hand,

$$
\lim _{\gamma \rightarrow \infty} W^{d}(\varrho, \gamma)=\lim _{\gamma \rightarrow \infty} W^{o}(\varrho, \gamma)>\lim _{\gamma \rightarrow \infty} W^{c}(\varrho, \gamma)
$$

as the allocations of local and national public goods under a decentralized system converge to the optimum as $\gamma$ goes to infinity.

Hence, it follows, by the intermediate value theorem, that $\exists^{1} \widehat{\gamma}: W^{c}(\varrho, \widehat{\gamma})=$ $W^{d}(\varrho, \widehat{\gamma})$

\section{B.3 Proof of proposition 3}

Let us first consider the case of exogenous spillovers, and take the following mapping: $\kappa=\kappa(\varrho, \gamma)=K o G^{d}(\varrho, \gamma)=K\left(G^{d}(\varrho, \gamma)\right)$, where $G^{d}(\varrho, \gamma)$ is defined as in equation (6) in text. That is, for $\gamma \in[0, \infty)$, there exists a unique level of $G \in[0, \infty)$ that originates a given amount of spillovers $\kappa \in[0,1)$, given $\varrho$, and it is convenient to take the rule $G^{d}(\varrho, \gamma)$ to be defined as in the decentralized solution.

Next, we solve both maximization problems presented in the text subject to this rule, and evaluate the objective functions at the solution. Letting $\widehat{W}^{c}(\varrho, \kappa)$ and $\widehat{W}^{d}(\varrho, \kappa)$ denote the welfare attained under centralization and decentralization respectively, we obtain:

$$
\begin{aligned}
\widehat{W}^{d}(\varrho, \kappa) & =\left(m_{1}+m_{2} \kappa\right) \cdot b\left(\widehat{g}_{1}^{d}(\varrho)\right)+\left(m_{2}+m_{1} \kappa\right) \cdot b\left(\widehat{g}_{2}^{d}(\varrho)\right)- \\
- & \rho\left(\widehat{g}_{1}^{d}(\varrho)+\widehat{g}_{2}^{d}(\varrho)\right)-\gamma K^{-1}(\kappa) \\
\widehat{W}^{c}(\varrho, \kappa) & =\left(m_{1}+m_{2}\right) \cdot(1+\kappa) \cdot b\left(\widehat{g}^{c}(\varrho, \kappa)\right)-2 \rho \widehat{g}^{c}(\varrho, \kappa)-\gamma K^{-1}(\kappa)
\end{aligned}
$$

where:

$\widehat{g}_{k}^{d}(\varrho)=\left\{x: b^{\prime}(x)=\frac{\rho}{m_{k}}\right\}, k=1,2 \quad$ and $\quad \widehat{g}^{c}(\varrho, \kappa)=\left\{x: b^{\prime}(x)=\frac{\rho}{\bar{m}(1+\kappa)}\right\}$

Now, let us return to the present case with endogenous spillovers. In the decentralized system, the level of the national public good is defined by $G^{d}$, which was used in the mapping above. Hence, welfare remains unchanged when compared to exogenous spillovers, i.e., $\widehat{W}^{d}(\varrho, \kappa)=W^{d}(\varrho, \gamma)$. As for centralization, observe that the problem solved in the text is just the unconstrained 
version of the maximization problem presented above. It follows that the objective function evaluated at the solution can be no lower than $\widehat{W}^{c}(\varrho, \kappa)$. That is:

$$
W^{c}(\varrho, \gamma)=\max _{g, G} S^{c}(g, G ; \varrho, \gamma) \geq \max _{g} \widehat{S}^{c}(g ; \varrho, \kappa)=\widehat{W}^{c}(\varrho, \kappa)
$$

where:

$$
S^{c}(g, G ; \varrho, \gamma)=\left(m_{1}+m_{2}\right) \cdot[1+K(G)] \cdot b(g)-2 \rho g-\gamma G
$$

and:

$$
\widehat{S}^{c}(g ; \varrho, \kappa)=\left(m_{1}+m_{2}\right) \cdot[1+\kappa] \cdot b(g)-2 \rho g-\gamma K^{-1}(\kappa)
$$

Hence,

$$
W^{c}(\varrho, \gamma)-W^{d}(\varrho, \gamma) \geq \widehat{W}^{c}(\varrho, \kappa)-\widehat{W}^{d}(\varrho, \kappa)
$$

It follows that, for all vectors $\left(\varrho^{0}, \gamma^{0}\right)$ such that

$$
\widehat{W}^{c}\left(\varrho^{0}, \kappa\left(\varrho^{0}, \gamma^{0}\right)\right)-\widehat{W}^{d}\left(\varrho^{0}, \kappa\left(\varrho^{0}, \gamma^{0}\right)\right)=0
$$

the introduction of endogenous spillovers will never put centralization in a lower standard as compared to decentralization, i.e., $W^{c}\left(\varrho^{0}, \gamma^{0}\right)-W^{d}\left(\varrho^{0}, \gamma^{0}\right) \geq 0$. Thus, there exists an interval in the space $(\varrho, \gamma)$ such that $\widehat{W}^{c}(\varrho, \kappa(\varrho, \gamma))-$ $\widehat{W}^{d}(\varrho, \kappa(\varrho, \gamma)) \leq 0$, but $W^{c}(\varrho, \gamma)-W^{d}(\varrho, \gamma) \geq 0$, which implies proposition 3.

\section{B.4 Proof of proposition 4}

From our previous discussion, it is clear that:

$$
\lim _{\gamma \rightarrow 0} E W^{p c}(\varrho, \gamma)=\lim _{\gamma \rightarrow 0} W^{o}(\varrho, \gamma)>\lim _{\gamma \rightarrow 0} E W^{p d}(\varrho, \gamma)
$$

and:

$$
\lim _{\gamma \rightarrow \infty} E W^{p d}(\varrho, \gamma)=\lim _{\gamma \rightarrow \infty} W^{o}(\varrho, \gamma)>\lim _{\gamma \rightarrow \infty} E W^{p c}(\varrho, \gamma)
$$

By continuity, the proposition follows immediately.

Observe that monotonicity cannot be assured, and thereby the behavior of $E W^{p c}(\varrho, \gamma)-E W^{p d}(\varrho, \gamma)$ cannot be ascertain for intermediate values of $\gamma$.

\section{B.5 Proof of proposition 5}

It is obvious that:

$$
\lim _{\gamma \rightarrow \infty} E W^{p d}(\varrho, \gamma)=\lim _{\gamma \rightarrow \infty} W^{o}(\varrho, \gamma)>\lim _{\gamma \rightarrow \infty} E W^{p c}(\varrho, \gamma)
$$

for which case decentralization dominates centralization. On the other hand, as $\gamma$ approaches zero, the relationship between $E W^{p d}(\varrho, \gamma)$ and $E W^{p c}(\varrho, \gamma)$ cannot be traced down. Two situations may occur: first, if $\lim _{\gamma \rightarrow 0} E W^{p d}(\varrho, \gamma)>$ $\lim _{\gamma \rightarrow 0} E W^{p c}(\varrho, \gamma)$, then decentralization may dominate centralization for all possible values of $\gamma$; second, if $\lim _{\gamma \rightarrow 0} E W^{p d}(\varrho, \gamma)<\lim _{\gamma \rightarrow 0} E W^{p c}(\varrho, \gamma)$, centralization dominates decentralization for low values of $\gamma$. 


\section{B.6 Proof of proposition 6}

We divide the proof in several steps.

\section{Connecting exogenous spillovers to endogenous spillovers}

Let us define the following virtual element:

$$
\begin{aligned}
\widetilde{W}^{p d}(\varrho, G) & =m_{1}\left[b\left(g_{1}^{p d}(\varrho)\right)+K(G) \cdot b\left(g_{2}^{p d}(\varrho)\right)\right]+ \\
& +m_{2}\left[b\left(g_{2}^{p d}(\varrho)\right)+K(G) \cdot b\left(g_{1}^{p d}(\varrho)\right)\right]- \\
& -\rho\left(g_{1}^{p d}(\varrho)+g_{2}^{p d}(\varrho)\right)-\gamma G
\end{aligned}
$$

where $g_{k}^{p d}(\varrho)=\left\{x: b^{\prime}(x)=\frac{\rho}{m_{k}}\right\}, k=1,2$. Also, consider the following application:

$$
\kappa^{p}=\kappa^{p}(\varrho, \gamma)=K o G^{p}(\varrho, \gamma)=K\left(G^{p}(\varrho, \gamma)\right)
$$

which maps the level of spillovers, $\kappa^{p}$, to their cost, $\gamma$, through the function $G^{p}(\varrho, \gamma)$. Assume, for now, that this application exists and is well defined (below we prove that this is in fact true). Hence, the welfare under exogenous spillovers can be written as:

$$
\widehat{W}^{p d}\left(\varrho, \kappa^{p}\right)=\widetilde{W}^{p d}\left(\varrho, G^{p}(\varrho, \gamma)\right)
$$

While the expected welfare with endogenous spillovers is:

$$
E W^{p d}(\varrho, \gamma)=\frac{1}{2}\left[\widetilde{W}^{p d}\left(\varrho, G_{1}^{p d}(\varrho, \gamma)\right)+\widetilde{W}^{p d}\left(\varrho, G_{2}^{p d}(\varrho, \gamma)\right)\right]
$$

Now, we choose $G^{p}(\varrho, \gamma)$ so that the expected welfare in a decentralized system with endogenous spillovers coincides with that of exogenous spillovers. We are allowed to do this because the rules for local public good provision are the same, i.e., $g_{k}^{p d}(\varrho)$ does not depend on the type of spillovers we consider (see below). Hence, $G^{p}(\varrho, \gamma)$ is defined implicitly by:

$$
\widetilde{W}^{p d}\left(\varrho, G^{p}(\varrho, \gamma)\right)=\frac{1}{2}\left[\widetilde{W}^{p d}\left(\varrho, G_{1}^{p d}(\varrho, \gamma)\right)+\widetilde{W}^{p d}\left(\varrho, G_{2}^{p d}(\varrho, \gamma)\right)\right]
$$

It remains to prove existence. As $\widetilde{W}^{p d}(\varrho, G)$ is everywhere concave in $G$, then there exists one $\widetilde{G} \in\left[\widetilde{G}_{2}, \widetilde{G}_{1}\right], G_{2} \leq G_{1}$ such that:

$$
\widetilde{W}^{p d}(\varrho, \widetilde{G})=\frac{1}{2}\left[\widetilde{W}^{p d}\left(\varrho, \widetilde{G}_{1}\right)+\widetilde{W}^{p d}\left(\varrho, \widetilde{G}_{2}\right)\right]
$$

which implies that the rule $G^{p}(\varrho, \gamma)$ exists and is well defined. 


\section{The case of exogenous spillovers}

Now, we follow the same steps as in section 5 to find the levels of local public goods, both for centralization and decentralization, subject to the rule $\kappa^{p}$, and evaluate the welfare in jurisdiction 1 and 2 . Let $\widehat{W}_{1}^{p d}\left(\varrho, \kappa^{p}\right)$ and $\widehat{W}_{2}^{p d}\left(\varrho, \kappa^{p}\right)$ denote these levels of welfare for decentralization, where the index denotes the jurisdiction in which welfare is being evaluated. Hence:

$$
\begin{aligned}
& \widehat{W}_{1}^{p d}\left(\varrho, \kappa^{p}\right)=m_{1}\left[b\left(\widehat{g}_{1}^{p d}(\varrho)\right)+\kappa^{p} b\left(\widehat{g}_{2}^{p d}(\varrho)\right)\right]-\rho \widehat{g}_{1}^{p d}(\varrho)-\frac{\gamma}{2} K^{-1}\left(\kappa^{p}\right) \\
& \widehat{W}_{2}^{p d}\left(\varrho, \kappa^{p}\right)=m_{2}\left[b\left(\widehat{g}_{2}^{p d}(\varrho)\right)+\kappa^{p} b\left(\widehat{g}_{1}^{p d}(\varrho)\right)\right]-\rho \widehat{g}_{2}^{p d}(\varrho)-\frac{\gamma}{2} K^{-1}\left(\kappa^{p}\right)
\end{aligned}
$$

where $\widehat{g}_{k}^{p d}(\varrho)=g_{k}^{p d}(\varrho), k=1,2$. Also, let:

$$
\widehat{W}^{p d}\left(\varrho, \kappa^{p}\right)=\widehat{W}_{1}^{p d}\left(\varrho, \kappa^{p}\right)+\widehat{W}_{2}^{p d}\left(\varrho, \kappa^{p}\right)
$$

For centralization, let $\widehat{W}_{k, l}^{p c}\left(\varrho, \kappa^{p}\right)$ and $\widehat{g}_{k, l}^{p c}\left(\varrho, \kappa^{p}\right)$ define respectively the level of welfare and the supply of the local public good in jurisdiction $k$ if the appointed agenda setter in the national legislature belongs to jurisdiction $l$.

The objective of the legislator is, in this case, to maximize his utility subject to the rule defined above. This yields a level of welfare given by:

$$
\begin{aligned}
\widehat{W}_{k, k}^{p c}\left(\varrho, \kappa^{p}\right) & =m_{k}\left[b\left(\widehat{g}_{k, k}^{p c}(\varrho)\right)+\kappa^{p} b\left(\widehat{g}_{l, k}^{p c}\left(\varrho, \kappa^{p}\right)\right)\right]- \\
& -\frac{\rho}{2}\left(\widehat{g}_{k, k}^{p c}(\varrho)+\widehat{g}_{l, k}^{p c}\left(\boldsymbol{\varrho}, \kappa^{p}\right)\right)-\frac{\gamma}{2} K^{-1}\left(\kappa^{p}\right) \\
\widehat{W}_{k, l}^{p c}\left(\varrho, \kappa^{p}\right) & =m_{k}\left[b\left(\widehat{g}_{k, l}^{p c}\left(\varrho, \kappa^{p}\right)\right)+\kappa^{p} b\left(\widehat{g}_{l, l}^{p c}(\varrho)\right)\right]- \\
& -\frac{\rho}{2}\left(\widehat{g}_{k, l}^{p c}\left(\varrho, \kappa^{p}\right)+\widehat{g}_{l, l}^{p c}(\varrho)\right)-\frac{\gamma}{2} K^{-1}\left(\kappa^{p}\right)
\end{aligned}
$$

where $\widehat{g}_{k, k}^{p c}(\varrho)=\left\{x: b^{\prime}(x)=\frac{\rho}{2 m_{k}}\right\}, \widehat{g}_{k, l}^{p c}\left(\varrho, \kappa^{p}\right)=\left\{x: b^{\prime}(x)=\frac{\rho}{2 m_{l} \kappa^{p}}\right\}$, $\widehat{g}_{l, k}^{p c}\left(\varrho, \kappa^{p}\right)=\left\{x: b^{\prime}(x)=\frac{\rho}{2 m_{k} \kappa^{p}}\right\}$ and $\widehat{g}_{l, l}^{p c}(\varrho)=\left\{x: b^{\prime}(x)=\frac{\rho}{2 m_{l}}\right\}$, for $k, l=1,2, k \neq l$. The expected welfare can then be computed:

$$
\widehat{E W}^{p c}\left(\varrho, \kappa^{p}\right)=\frac{1}{2}\left[\widehat{W}_{1,1}^{p c}\left(\varrho, \kappa^{p}\right)+\widehat{W}_{2,1}^{p c}\left(\varrho, \kappa^{p}\right)+\widehat{W}_{1,2}^{p c}\left(\varrho, \kappa^{p}\right)+\widehat{W}_{2,2}^{p c}\left(\varrho, \kappa^{p}\right)\right]
$$

\section{The case of endogenous spillovers}

Now, let us return to the case where spillovers are endogenous. In the decentralized system, it is immediate that the solution coincides with the one set above, by construction. Hence, it follows that $E W^{p d}(\varrho, \gamma)=\widehat{W}^{p d}\left(\varrho, \kappa^{p}\right)$.

For centralization, let $W_{k, l}^{p c}(\varrho, \gamma)$ define the welfare in jurisdiction $k$ if the appointed agenda setter in the national legislature belongs to jurisdiction $l$, and observe that the winning politician is maximizing his welfare, with one extra degree of freedom as compared to the case of exogenous spillovers - this is the endogenous spillover effect. Thereby, $W_{k, k}^{p c}(\varrho, \gamma) \geq \widehat{W}_{k, k}^{p c}\left(\varrho, \kappa^{p}\right), k=1,2$. Regarding jurisdiction $l$, the above rule may be or not welfare improving, since this region does not show up in the maximization problem of the agenda setter. 
This means that both the endogenous spillover effect - which is due to the enlargement in the choice vector of the agenda setter -, and the misallocation effect - which results from the fact that the welfare in jurisdiction $l$ is ignored for the choice of the relevant policy vector -, may influence the outcome in this jurisdiction. As the former is clearly positive and the latter clearly negative, this results in a dubious evaluation of the introduction of endogenous spillovers. Hence:

$$
W_{k, l}^{p c}(\varrho, \gamma) \lesseqgtr \widehat{W}_{k, l}^{p c}\left(\varrho, \kappa^{p}\right) ; k, l=1,2 ; k \neq l
$$

Finally, let:

$$
E W^{p c}(\varrho, \gamma)=\frac{1}{2}\left[W_{1,1}^{p c}(\varrho, \gamma)+W_{2,1}^{p c}(\varrho, \gamma)+W_{1,2}^{p c}(\varrho, \gamma)+W_{2,2}^{p c}(\varrho, \gamma)\right]
$$

Collecting the effects, we get:

$$
\begin{aligned}
& E W^{p c}(\varrho, \gamma)-\widehat{E W}^{p c}\left(\varrho, \kappa^{p}\right)= \\
= & \frac{1}{2}[\underbrace{\left(W_{1,1}^{p c}(\varrho, \gamma)-\widehat{W}_{1,1}^{p c}\left(\varrho, \kappa^{p}\right)\right)}_{\geq 0}+\underbrace{\left(W_{2,2}^{p c}(\varrho, \gamma)-\widehat{W}_{2,2}^{p c}\left(\varrho, \kappa^{p}\right)\right)}_{\geq 0}]+ \\
+ & \frac{1}{2}[\underbrace{\left(W_{2,1}^{p c}(\varrho, \gamma)-\widehat{W}_{2,1}^{p c}\left(\varrho, \kappa^{p}\right)\right)}_{\lesseqgtr 0}+\underbrace{\left(W_{1,2}^{p c}(\varrho, \gamma)-\widehat{W}_{1,2}^{p c}\left(\varrho, \kappa^{p}\right)\right)}_{\lesseqgtr 0}]
\end{aligned}
$$

The first two terms are only affected by the endogenous spillover effect, and are clearly non-negative. However, the last two are endowed with both the endogenous spillover effect and the misallocation effect, and hence the sign is unclear, depending on which effect dominates. Clearly, the impact on welfare of introducing endogenous spillovers depends on the balance between these two forces, as the misallocation effect on the last two terms may overcome all benefits generated by introducing endogenous spillovers.

\section{B.7 Proof of proposition 7}

Under $b(g)=g^{0.5}$, the provision of public goods become:

- Under centralization with no separation of powers:

$$
g_{1,1}^{p c}=\frac{m_{1}}{\rho} ; g_{2,1}^{p c}=\frac{m_{1}}{\rho} K\left(G_{1}^{p c}\right) ; g_{1,2}^{p c}=\frac{m_{2}}{\rho} K\left(G_{2}^{p c}\right) ; g_{2,2}^{p c}=\frac{m_{2}}{\rho}
$$

where $G_{k}^{p c}$ is defined by:

$$
\frac{m_{k}^{2}}{\rho} K\left(G_{k}^{p c}\right) K^{\prime}\left(G_{k}^{p c}\right)=\frac{\gamma}{2}
$$

- Under centralization with separation of powers:

$$
g_{1,1}^{p c s}=\frac{m_{1}}{\rho} ; g_{2,1}^{p c s}=\frac{m_{1}}{\rho} K\left(G_{1,2}^{p c s}\right) ; g_{1,2}^{p c s}=\frac{m_{2}}{\rho} K\left(G_{2,1}^{p c s}\right) ; g_{2,2}^{p c s}=\frac{m_{2}}{\rho}
$$


where $G_{k, l}^{p c s}$ is defined by:

$$
\frac{m_{l} m_{k}}{\rho} K^{\prime}\left(G_{k, l}^{p c s}\right)=\frac{\gamma}{2} ; k \neq l
$$

As we can observe, the rules for local public good provision are the same, what changes between systems is the level of the national public good. Let us define the following hypothetical expected welfare as a function of $G$ :

$$
\widetilde{E W}\left(\varrho, \gamma, G_{1}, G_{2}\right)=\frac{1}{2}\left[\widetilde{W}_{1}^{p c}\left(\varrho, \gamma, G_{1}\right)+\widetilde{W}_{2}^{p c}\left(\varrho, \gamma, G_{2}\right)\right]
$$

where,

$$
\begin{aligned}
\widetilde{W}_{1}\left(\varrho, \gamma, G_{1}\right) & =\left[m_{1}\left(\frac{m_{1}}{\rho}+K^{2}\left(G_{1}\right) \frac{m_{1}}{\rho}\right)+2 \frac{m_{1} m_{2} K\left(G_{1}\right)}{\rho}\right]- \\
& -\left[\rho\left(\left(\frac{m_{1}}{\rho}\right)^{2}+\left(\frac{m_{1} K\left(G_{1}\right)}{\rho}\right)^{2}\right)+\gamma G_{1}\right]= \\
& =2 \frac{m_{1} m_{2} K\left(G_{1}\right)}{\rho}-\gamma G_{1}
\end{aligned}
$$

and,

$$
\begin{aligned}
\widetilde{W}_{2}\left(\varrho, \gamma, G_{2}\right) & =\left[m_{2}\left(\frac{m_{2}}{\rho}+K^{2}\left(G_{2}\right) \frac{m_{2}}{\rho}\right)+2 \frac{m_{2} m_{1} K\left(G_{2}\right)}{\rho}\right]- \\
& -\left[\rho\left(\left(\frac{m_{2}}{\rho}\right)^{2}+\left(\frac{m_{2} K\left(G_{2}\right)}{\rho}\right)^{2}\right)+\gamma G_{2}\right]= \\
& =2 \frac{m_{2} m_{1} K\left(G_{2}\right)}{\rho}-\gamma G_{2}
\end{aligned}
$$

The term $\widetilde{W}_{k}\left(\varrho, \gamma, G_{k}\right)$ is the hypothetical welfare if the policy maker in jurisdiction $k$ is selected to set the supply of local public goods. It follows that $\widetilde{E W}\left(\varrho, \gamma, G_{1}, G_{2}\right)$ is the hypothetical expected welfare of the society. If $G_{k}=G_{k}^{p c}, k=1,2$, then $\widetilde{E W}\left(\varrho, \gamma, G_{1}, G_{2}\right)$ delivers the expected welfare under no separation of powers, while, if $G_{k}=G_{k, l}^{p c s} ; k, l=1,2 ; k \neq l, \widetilde{E W}\left(\varrho, \gamma, G_{1}, G_{2}\right)$ yields the expected welfare with separation of powers.

Consider now the level of $G_{k}$ that maximizes $\widetilde{W}_{k}\left(\varrho, \gamma, G_{k}\right)$, and let this be denoted by $G_{k}^{*}$ :

$$
\begin{aligned}
& \frac{\mathrm{d} \widetilde{E W}_{k}\left(\varrho, \gamma, G_{k}\right)}{\mathrm{d} G}=0 \Leftrightarrow \\
\Leftrightarrow & 2 \frac{m_{k} m_{l} K^{\prime}\left(G_{k}^{*}\right)}{\rho}=\gamma ; k, l=1,2 ; k \neq l
\end{aligned}
$$

It is immediate to observe that $G_{k}^{*}$ is a maximum, since:

$$
\frac{\mathrm{d}^{2} \widetilde{W}_{k}\left(\varrho, \gamma, G_{k}\right)}{\mathrm{d} G^{2}}=\frac{2 m_{k} m_{l} K^{\prime \prime}\left(G_{k}\right)}{\rho}<0 ; k, l=1,2 ; k \neq l
$$


Observe that the FOC of this problem yields exactly the same solution as the centralized system with separation of powers. Consequently, $G_{k}^{*}=G_{k, l}^{p c s}$, and:

$$
\widetilde{W}_{k}\left(\varrho, \gamma, G_{k}^{*}\right)=\widetilde{W}_{k}\left(\varrho, \gamma, G_{k, l}^{p c s}\right) \geq \widetilde{W}_{k}\left(\varrho, \gamma, G_{k}^{p c}\right) ; k=1,2 ; k \neq l
$$

It follows immediately that:

$$
\widetilde{E W}\left(\varrho, \gamma, G_{1,2}^{p c s}, G_{2,1}^{p c s}\right) \geq \widetilde{E W}\left(\varrho, \gamma, G_{1}^{p c}, G_{2}^{p c}\right)
$$

Finally, noting that, by definition, $\widetilde{E W}\left(\varrho, \gamma, G_{1,2}^{p c s}, G_{2,1}^{p c s}\right)=E W^{p c s}(\varrho, \gamma)$ and $\widetilde{E W}\left(\varrho, \gamma, G_{1}^{p c}, G_{2}^{p c}\right)=E W^{p c}(\varrho, \gamma)$, the result follows.

\section{B.8 Proof of proposition 8}

The result follows from the proofs of proposition 6 and 7 , and so we only provide a brief sketch to the proof. As the decentralized regime does not change relative to the case with no separation of powers, we can take the mapping $\kappa=K o G^{p}(\gamma)$ defined in the proof of proposition 6 , which equalizes the expected welfare in a decentralized system with exogenous and endogenous spillovers. This provides the basis for comparison.

Next, we allow the centralized system with separation of powers to optimize, and compare the result with the expected welfare under the assumption of exogenous spillovers. From the proof of proposition 7, we know that the outcome under centralization with endogenous spillovers maximizes the expected welfare of the economy, $\widetilde{E W}\left(\varrho, \gamma, G_{1}, G_{2}\right)$, and therefore it must follow that, once we consider exogenous spillovers, the expected welfare cannot increase:

$$
\widetilde{E W}\left(\varrho, \gamma, G_{1,2}^{p c s}, G_{2,1}^{p c s}\right) \geq \widetilde{E W}\left(\varrho, \gamma, K^{-1}\left(\kappa^{p}\right), K^{-1}\left(\kappa^{p}\right)\right)
$$

\section{Maximization issues}

\section{C.1 Derivation of the optimal solution}

Recall that the problem to solve is:

$$
\max _{\mathbf{g}, G}\left[m_{1}+m_{2} K(G)\right] \cdot b\left(g_{1}\right)+\left[m_{2}+m_{1} K(G)\right] \cdot b\left(g_{2}\right)-\rho\left(g_{1}+g_{2}\right)-\gamma G
$$

The First Order Conditions (FOC) w.r.t. $g_{1}$ and $g_{2}$ yield:

$$
\begin{aligned}
b^{\prime}\left(g_{1}^{o}(G)\right) & =\frac{\rho}{m_{1}+m_{2} K(G)} \\
b^{\prime}\left(g_{2}^{o}(G)\right) & =\frac{\rho}{m_{2}+m_{1} K(G)}
\end{aligned}
$$

These conditions allow us to write the FOC w.r.t. $G$ as:

$$
\left[m_{1} b\left(g_{2}^{o}(G)\right)+m_{2} b\left(g_{1}^{o}(G)\right)\right] \cdot K^{\prime}(G)=\gamma
$$


Now, let:

$$
\varphi(G)=\left[m_{1} b\left(g_{2}^{o}(G)\right)+m_{2} b\left(g_{1}^{o}(G)\right)\right] \cdot K^{\prime}(G)-\gamma
$$

Since $g_{1}^{o}(G)>0$ and $g_{2}^{o}(G)>0 \forall G$, we have that $\lim _{G \rightarrow 0} \varphi(G)=\infty$ and $\lim _{G \rightarrow \infty} \varphi(G)=-\gamma$. As by assumption $\left[m_{1} b\left(g_{2}^{o}(G)\right)+m_{2} b\left(g_{1}^{o}(G)\right)\right] \cdot K^{\prime}(G)$ is decreasing in $G$, there exists a unique $G^{*}$ such that $\varphi\left(G^{*}\right)=0$. Letting $G^{*}=G^{o}$, the above conditions define the triplet $\left(g_{1}^{o}, g_{2}^{o}, G^{o}\right)$ described in the text.

To check that the vector $\left(g_{1}^{o}, g_{2}^{o}, G^{o}\right)$ represents a maximizer, let us start by defining $\left|\mathcal{H}_{z}(\mathbf{g}, G)\right|$ as the determinant of the Hessian after deleting the last $3-z$ rows and columns. Some algebra allows us to conclude that $\left|\mathcal{H}_{1}(\mathrm{~g}, G)\right|<$ 0 and $\left|\mathcal{H}_{2}(\mathbf{g}, G)\right|>0$. In order to prove that $\left|\mathcal{H}_{3}(\mathbf{g}, G)\right|<0$, we must take the derivative of $\left[m_{1} b\left(g_{2}^{o}(G)+m_{2} b\left(g_{1}^{o}(G)\right] \cdot K^{\prime}(G)\right.\right.$ with respect to $G$ (which is negative, by assumption) and use it in the expression for $\left|\mathcal{H}_{3}(\mathrm{~g}, G)\right|$. As this is extremely cumbersome, we omit the technical details.

\section{C.2 Derivation of the centralized solution}

The problem to solve is:

$$
\max _{g, G}\left(m_{1}+m_{2}\right) \cdot[1+K(G)] \cdot b(g)-2 \rho g-\gamma G
$$

The FOCs w.r.t. the vector $(g, G)$ read:

$$
b^{\prime}\left(g^{c}(G)\right)=\frac{\rho}{\bar{m}[1+K(G)]} \quad \text { and } \quad \bar{m} b\left(g^{c}(G)\right) \cdot K^{\prime}(G)=\frac{\gamma}{2}
$$

where $\bar{m}=\frac{m_{1}+m_{2}}{2}$. Similarly to the previous case, we take $\bar{m} b\left(g^{c}(G)\right) \cdot K^{\prime}(G)$ to be decreasing in $G$, so that there exists a unique $G^{*}$ such that:

$$
\bar{m} b\left(g^{c}\left(G^{*}\right)\right) \cdot K^{\prime}\left(G^{*}\right)=\frac{\gamma}{2}
$$

Letting $G^{c}=G^{*}$, we obtain the maximizing vector $\left(g^{c}, G^{c}\right)$ defined in the text.

Proving that the vector $\left(g^{c}, G^{c}\right)$ defines a maximizer follows the same steps as for the optimal solution.

\section{Writing expected welfare as intermediate pref- erences}

Let us write $E W_{k}^{\theta}\left(\theta_{k}, \theta_{l}\right)$ as follows:

$$
E W_{k}^{\theta}\left(\theta_{k}, \theta_{l}\right)=J\left(\theta_{k}, \theta_{l}\right)+\theta H\left(\theta_{k}, \theta_{l}\right)
$$

where:

$$
\begin{aligned}
J\left(\theta_{k}, \theta_{l}\right)= & -\frac{1}{2}\left[\rho \frac{g_{k}\left(\theta_{k}\right)+g_{l}\left(\theta_{k}, G_{k}\left(\theta_{k}\right)\right)}{2}+\frac{\gamma}{2} G_{k}\left(\theta_{k}\right)\right]- \\
& -\frac{1}{2}\left[\rho \frac{g_{k}\left(\theta_{l}, G_{l}\left(\theta_{l}\right)\right)+g_{l}\left(\theta_{l}\right)}{2}+\frac{\gamma}{2} G_{l}\left(\theta_{l}\right)\right]
\end{aligned}
$$


and,

$$
\begin{aligned}
H\left(\theta_{k}, \theta_{l}\right) & =\frac{1}{2}\left[b\left(g_{k}\left(\theta_{k}\right)\right)+K\left(G_{k}\left(\theta_{k}\right)\right) \cdot b\left(g_{l}\left(\theta_{k}, G_{k}\left(\theta_{k}\right)\right)\right)\right]+ \\
& +\frac{1}{2}\left[b\left(g_{k}\left(\theta_{l}, G_{l}\left(\theta_{l}\right)\right)\right)+K\left(G_{l}\left(\theta_{l}\right)\right) \cdot b\left(g_{l}\left(\theta_{l}\right)\right)\right]
\end{aligned}
$$

Noticing that $J\left(\theta_{k}, \theta_{l}\right)$ and $H\left(\theta_{k}, \theta_{l}\right)$ are equal for all voters in jurisdiction $k$, the result follows immediately. 